\title{
Consenso colombiano de expertos sobre recomendaciones basadas en evidencia para el diagnóstico y el tratamiento de alteraciones del metabolismo óseo y mineral en pacientes con enfermedad renal crónica
}

\author{
Jorge Antonio Coronado Daza (DD $\square^{1,2,3}$, Erica Yamile Yama Mosquera ${ }^{10}{ }^{1,4,5}$ \\ Mercedes Alfaro Tejeda (D) ${ }^{1,6}$ et al. \\ ${ }^{1}$ Asociación Colombiana de Nefrología e Hipertensión Arterial (Asocolnef). \\ ${ }^{2}$ Facultad de Medicina, Departamento médico, Universidad de Cartagena. \\ ${ }^{3}$ Nefrología y Diálisis SAS, Cartagena, Colombia. \\ ${ }^{4}$ Universidad Nueva Granada, Bogotá, Colombia. \\ ${ }^{5}$ Clínica Reina Sofía, Bogotá, Colombia. \\ ${ }^{6}$ Corporación Universitaria Rafael Núñez, Cartagena, Colombia.
}

Lista completa de autores

Cómo citar: Coronado Daza J, et al. Consenso colombiano de expertos sobre recomendaciones basadas en evidencia para el diagnóstico y el tratamiento de alteraciones del metabolismo óseo y mineral en pacientes con enfermedad renal crónica. Rev. Colomb. Nefrol. 2021 8(2), e565. https: //doi.org/10.22265/acnef.8.2.565

Recibido:

$\mathrm{xx} / \mathrm{xxx} / 2021$

Aceptado:

$\mathrm{xx} / \mathrm{xxx} / 2021$

Publicado:

10/Ago/2021

\section{Resumen}

Introducción: las alteraciones del metabolismo óseo y mineral asociado a la enfermedad renal crónica (AMOM-ERC) es una de las complicaciones más frecuentes e importantes que afecta la calidad de vida de pacientes con enfermedad renal crónica (ERC) y sus familias y, además, contribuye al aumento de la morbimortalidad cardiovascular.

Objetivo: el objetivo es generar recomendaciones informadas en la evidencia para el diagnóstico y tratamiento de las AMOM en pacientes con ERC, mediante un consenso de expertos.

$\checkmark$ Correspondencia: Universidad de Cartagena, Zaragocilla, Campus de la salud, Facultad de Medicina, Cartagena, Colombia. Correo electrónico: jcoronadod@unicartagena.edu.co 
Método: a partir de una revisión sistemática de: literatura en bases de datos Embase y Medline vía Pubmed, grupos desarrolladores de evidencia y sociedades científicas, se formularon recomendaciones preliminares por el grupo desarrollador que fueron consultadas a un colectivo experto en nefrología, endocrinología, geriatría, reumatología, medicina interna y cardiología, a través del método Delphi modificado.

Resultados: se presentan 62 recomendaciones sobre diagnóstico y tratamiento de AMOM-ERC, definidas por consenso entre 51 expertos clínicos y el grupo desarrollador. El rango de aprobación de las recomendaciones osciló entre $80,9 \%$ y $100 \%$.

Conclusión: as recomendaciones presentadas permiten a los expertos clínicos la toma de decisiones clínicas cotidianas basadas en evidencia sobre el diagnóstico y el tratamiento de las AMOM-ERC en Colombia.

Palabras clave: trastorno mineral y óseo asociado a la enfermedad renal crónica, insuficiencia renal crónica, calidad de vida, consenso, diagnóstico, terapéutica.

\section{Colombian consensus of experts on recommendations based on evidence for the diagnosis and treatment of alterations of bone and mineral metabolism in patients with chronic kidney disease}

\section{Abstract}

Background: Bone and mineral metabolism disorders associated with chronic kidney disease (MBD$\mathrm{CKD}$ ) is one of the most frequent and important complications that affects the quality of life of patients with chronic kidney disease and their families and also contributes to the increase of cardiovascular morbidity and mortality.

Objective: The objective is to generate evidence-informed recommendations for the diagnosis and treatment of bone and mineral metabolism disorders in patients with chronic kidney disease, using an expert consensus.

Method: A systematic review of the literature in the Embase and Medline databases, evidence development groups and scientific societies, preliminary recommendations were formulated by the developer group that were consulted with an expert group of nephrology, endocrinology, geriatrics, rheumatology, internal medicine and cardiology, through the modified Delphi method.

Results: 62 recommendations on diagnosis and treatment of MBD-CKD are presented, defined by consensus between 51 clinical experts and the developer group. The approval range of the recommendations ranged between $80.9 \%$ and $100 \%$.

Conclusions: The recommendations presented allow clinical experts to make daily clinical decisions based on evidence about the diagnosis and treatment of bone and mineral metabolism disorders in patients with chronic kidney disease in Colombia.

Keywords: Chronic Kidney Disease-Mineral and Bone Disorder, Renal Insufficiency Chronic, Quality of Life, Consensus, Diagnosis, Therapeutics. 


\section{Tabla de Contenidos}

Página

Introducción

Alcance y objetivos $\quad 6$

Título ............. 6

Objetivo.............. 7

Población objeto . . . . . . . . . 7

Población incluida . . . . . . . 7

Población no incluida . . . . . . 7

Aspectos clínicos . . . . . . . . 7

Usuarios . . . . . . . . . . 7

Metodología 7

Grupo desarrollador . . . . . . . . . . 7

Preguntas clínicas . . . . . . . . . . 8

Búsqueda de la evidencia . . . . . . . . 8

Fuentes de información . . . . . . . 9 9

Tamización y selección de la evidencia . 9

Evaluación de la calidad de la evidencia 10

Recomendaciones preliminares . . . . 10

Consenso formal de expertos . . . . . . 10

Graduación de recomendaciones . . . . 11

Resultados de la RS $\quad 11$

Diagnóstico . . . . . . . . . . . . 11

Tratamiento

18

Diagnóstico y tratamiento de la osteoporosis en ERC . . . . . . . . . 33

Conflicto de intereses $\quad 38$

Responsabilidades éticas $\quad 38$

Protección de personas y animales . . . 38

Confidencialidad de los datos . . . . . 38

Derecho a la privacidad y consentimiento informado . . . . . . 38

Contribución de los autores $\quad 38$

$\begin{array}{ll}\text { Referencias } & 38\end{array}$

Anexos $\quad 45$

Anexo A. Preguntas clínicas desarrolladas 45

Anexo B. Estrategias de búsqueda . . . 47

Anexo C. Diagrama de flujo - Prisma . . 48

Anexo D. Evaluación de calidad . . . . 49
Calificación de GPC . . . . . . . . 49

Calificación de RSL . . . . . . . 50

Calificación de ensayos clínicos . 51

Calificación de estudios primarios $\quad 52$

Calificación de estudios diagnósticos - Sprague $2016 \quad \ldots \quad 53$

Resultados de la votación de la consulta preconsenso . . . 54

Resultados de la votación de consenso de expertos (ronda 1 y 2$) \ldots \ldots \ldots$

\section{Índice de tablas}

Grupo desarrollador del consenso . . . 8

Conflicto de intereses declarado por los miembros del grupo de consenso . 39

Estrategias de búsqueda . . . . . . . . 47 


\section{Introducción}

En el año 2005, en Estados Unidos de América, la enfermedad renal crónica (ERC) fue declarada un problema de salud pública [1]. La ERC es altamente prevalente a nivel mundial, con una proporción global estimada del 13,4\% (de 11,7 a 15,1\%) y con variaciones regionales [2].

En general, la prevalencia es similar por sexo, afecta con mayor frecuencia a los pacientes por encima de los 55 años, predomina en la raza negra y en los estratos socioeconómicos bajos.

En Colombia, según el último reporte de la Cuenta de Alto Costo (CAC), la proporción de la ERC es de 1,8 por cada 100 habitantes, la incidencia de pacientes con ERC estadio 5 es de 10,3 por cada 100.000 habitantes, con prevalencia de 91 por cada 100.000 habitantes y una mortalidad cercana al $14 \%$.

La CAC es una organización creada en el 2008 con la finalidad de hacer seguimiento a enfermedades que demandan un alto consumo de los recursos sanitarios, entre ellos la ERC $[3,4]$. Por su parte, la prevalencia en Colombia está lejos del promedio mundial y se ha explicado por la existencia de un importante subregistro de datos para estimar la verdadera

\section{En este consenso se abordarán} específicamente las AMOM-ERC pacientes en riesgo de padecer ERC. Este fenómeno observado en Colombia puede explicar las diferencias en las prevalencias reportadas a nivel mundial que dependen de la confiabilidad de los datos recolectados y de las estrategias en políticas de salud existentes en los diferentes países.

La ERC es considerada una enfermedad sistémica que afecta desde el sistema inmune hasta órganos complejos como el corazón. Por ser un estado inflamatorio crónico con disfunción endotelial, se constituye en un factor de riesgo cardiovascular y contribuye a la alta mortalidad de estos pacientes por causa cardiovascular, tanto en prediálisis como en terapia dialítica [5].

Entre las principales complicaciones crónicas, en este consenso se abordarán específicamente las AMOM-ERC ( $C K D-M B D$ por su acrónimo en inglés), por ser unas de las complicaciones más frecuente e importantes por afectar la calidad de vida y contribuir al aumento de la morbimortalidad de origen cardiovascular. 
En 2005, en Madrid, España, se desarrolló la segunda conferencia “Controversias Kdigo (Kidney Disease: Improving Global Outcomes)” sobre 'Definición, evaluación y clasificación de la osteodistrofia renal'. En esta reunión se acordó dejar el término osteodistrofia renal exclusivamente para la patología ósea encontrada en una biopsia de hueso y se acuñó una nueva entidad clínica o síndrome denominado $C K D-M B D$, el cual incorpora elementos del metabolismo mineral anormal, alteraciones en la estructura y la composición del hueso y calcificaciones extraesqueléticas.

Se definieron entonces las AMOM-ERC como una alteración sistémica del metabolismo óseo y mineral debido a la ERC manifestada por una alteración o una combinación de los siguientes: anormalidades del calcio, fósforo, hormona paratiroidea (PTH) o del metabolismo de la vitamina $\mathrm{D}$; anormalidades en el recambio óseo, mineralización, volumen, crecimiento lineal o fuerza, y calcificación vascular o de otros tejidos blandos [6].

A nivel internacional, la prevalencia de $C K D-M B D$, que denominaremos en este consenso como AMOM-ERC, es variable, pero siempre presente en un porcentaje importante, tanto en pacientes en prediálisis como en diálisis. En el estudio de cohorte CKDopps [7] en el que participaron Brasil, Francia, Alemania, Japón y Estados Unidos, con 7.658 pacientes adultos con tasas de filtrado glomerular (TFG) menores de $60 \mathrm{ml} / \mathrm{min}$, se evidenció que más de dos tercios de los pacientes tenían marcadores de AMOM-ERC.

En Colombia, un estudio que incluyó 2.026 pacientes, de los cuales 1.756 tenían medición de PTH, encontró los siguientes resultados: deficiencia de vitamina D en el 78,16\%; hiperparatiroidismo secundario en el 63,67\%; e hiperfosfatemia en el 12,38\%,con aumento de la prevalencia a medida que progresaban los estadios de la ERC del 1 al 5 [8].

Si se toman como proyección los últimos datos públicos del informe de la CAC del 2019 [4] y se aplican los datos encontrados en el análisis anterior, se tendría alrededor de 27.000 pacientes con déficit de vitamina $\mathrm{D}, 22.000$ pacientes con hiperparatiroidismo secundario y 4.300 pacientes con hiperfosfatemia; esto sería equivalente a que toda su población tuviese algún grado de AMOM-ERC en municipios como Cerete, Calarcá, Caldas (Antioquia) o Copacabana, entre otros.

A la hora de hablar de carga de enfermedad en Colombia, la mortalidad por enfermedades no trasmisibles y la carga que ello causa a los sistemas de salud es alta en el tratamiento de la población en diálisis; los 34.658 pacientes en diálisis, reportados por la CAC en 2019, representan el 0,067\% de la población, sin embargo, es posible gastar entre el 4 y hasta el $12 \%$ 
de todo el presupuesto de salud, según cálculos de la literatura mundial [4,9-11].

Al tratar las alteraciones del metabolismo mineral y óseo podemos impactar en términos económicos; por ejemplo: controlar el hiperparatiroidismo secundario, ya que los tratamientos actuales son costo-efectivos (al considerar: costo de los medicamentos, cuidados habituales, eventos cardiovasculares, fracturas y paratiroidectomía, los cuales suman con el tratamiento habitual: 185.887 dólares americanos, comparado con los tratamientos actuales en 219.696 dólares americanos) y nos permiten ganar una unidad de QALY (años de vida ajustados por calidad), teniendo en cuenta no superan el umbral de los 100.000 dólares americanos [12].

Desde la primera publicación de las guías de práctica clínica (GPC) Kdigo sobre $C K D-M B D$ en 2009 y actualizadas en 2017, las diferentes sociedades científicas han realizado adaptaciones, adopciones y actualizaciones, con el objetivo de contextualizar esta entidad clínica en las realidades particulares regionales. Así, Slahn en 2013 propone las guías latinoamericanas para el abordaje de las AMOM-ERC, igualmente lo hacen sociedades como las de Argentina y España. En Colombia, la Asociación Colombiana de Nefrología (Asocolnef), y en particular el Comité de Metabolismo Óseo Mineral, han identificado esta problemática, por eso se ha desarrollado este consenso de expertos como una iniciativa necesaria al ofrecer una respuesta práctica, integrando los conceptos actuales y las definiciones conocidas como una respuesta a las preguntas clínicas de

\section{Se ha desarrollado bajo los estándares de la rigurosidad metodológica} relevancia.

Este ejercicio académico, donde han participado en su evaluación especialidades afines a la nefrología que también manejan pacientes con AMOM-ERC como endocrinología, reumatología, cardiología y medicina interna, se ha desarrollado bajo los estándares de la rigurosidad metodológica, los cuales permiten emanar recomendaciones que se esperan sean de la utilidad clínica y aplicables en nuestro ejercicio clínico diario.

\section{Alcance y objetivos}

\section{Título}

Consenso colombiano de expertos sobre recomendaciones basadas en evidencia para el diagnóstico y el tratamiento de AMOM en pacientes con ERC. 


\section{Objetivo}

Generar recomendaciones informadas en la evidencia para el diagnóstico y el tratamiento de las AMOM en pacientes con ERC, mediante un consenso de expertos.

\section{Población objeto}

\section{Población incluida}

Pacientes de 18 años o más con diagnóstico de ERC y sospecha o diagnóstico de las AMOMERC.

\section{Población no incluida}

Pacientes menores de 18 años y mujeres embarazadas.

\section{Aspectos clínicos}

En el consenso se incluyen recomendaciones acerca del diagnóstico y el tratamiento de las AMOM-ERC.

\section{Usuarios}

Los usuarios directos de las recomendaciones basadas en evidencia aprobadas por el colectivo experto incluyen médicos generales, especialistas y demás profesionales de la salud involucrados en la atención de pacientes con diagnóstico de ERC y sospecha o confirmación de AMOM-ERC.

\section{Metodología}

Al tener en cuenta la necesidad de generar recomendaciones basadas en la evidencia que orienten la práctica clínica respecto al diagnóstico y el tratamiento de AMOM-ERC, las preguntas de interés del grupo desarrollador se abordaron mediante la revisión de literatura y el consenso de expertos.

\section{Grupo desarrollador}

El grupo desarrollador estuvo conformado por expertos clínicos especialistas en nefrología con experiencia en el manejo de pacientes con AMOM-ERC. Asimismo, se contó con epidemiólogos clínicos expertos en búsqueda sistemática de la literatura, calificación de la calidad 
de evidencia y desarrollo de consenso de expertos. En la Tabla 1 se presenta cada integrante del grupo desarrollador, su perfil profesional y su rol en el desarrollo de la guía.

Tabla 1. Grupo desarrollador del consenso

\begin{tabular}{|c|c|c|c|}
\hline Nombre & Perfil profesional & $\begin{array}{l}\text { Rol en el desarrollo } \\
\text { de la guía }\end{array}$ & Afiliación \\
\hline Jorge Antonio Coronado Daza & $\begin{array}{l}\text { Médico, internista nefrólogo, } \\
\text { MSc. en Epidemiología Clínica, PhD. en } \\
\text { Metodología de la Investigación Biomédica } \\
\text { y Salud Pública }\end{array}$ & $\begin{array}{l}\text { Líder del comité } \\
\text { de expertos }\end{array}$ & $\begin{array}{l}\text { Asociación Colombiana de Nefrología } \\
\text { e Hipertensión Arterial / Universidad de } \\
\text { Cartagena / Nefrología y Diálisis SAS }\end{array}$ \\
\hline Erica Yamile Yama Mosquera & Médica, internista y nefróloga & Experta clínica & $\begin{array}{l}\text { Asociación Colombiana de Nefrología } \\
\text { e Hipertensión Arterial / Universidad Nueva } \\
\text { Granada / Clínica Reina Sofía }\end{array}$ \\
\hline Mercedes Alfaro Tejeda & Médica, nefróloga & Experta clínica & $\begin{array}{l}\text { Asociación Colombiana de Nefrología } \\
\text { e Hipertensión Arterial / Universidad Rafael Núñez }\end{array}$ \\
\hline Juan Guillermo Guevara García & Médico, internista, nefrólogo & Experto clínico & $\begin{array}{l}\text { Asociación Colombiana de Nefrología } \\
\text { e Hipertensión Arterial }\end{array}$ \\
\hline Astrid Patricia Hernández Sierra & Médica, nefróloga & Experta clínica & $\begin{array}{l}\text { Asociación Colombiana de Nefrología } \\
\text { e Hipertensión Arterial }\end{array}$ \\
\hline José Javier Arango Álvarez & Médico, internista, nefrólogo & Experto clínico & $\begin{array}{l}\text { Asociación Colombiana de Nefrología } \\
\text { e Hipertensión Arterial }\end{array}$ \\
\hline Elizabeth Álzate Herrera & Médica, nefróloga & Experta clínica & $\begin{array}{l}\text { Asociación Colombiana de Nefrología } \\
\text { e Hipertensión Arterial }\end{array}$ \\
\hline Andrés Hernández Coronado & Médico, nefrólogo & Experto clínico & $\begin{array}{l}\text { Asociación Colombiana de Nefrología } \\
\text { e Hipertensión Arterial }\end{array}$ \\
\hline César Augusto Restrepo Valencia & Médico, internista y nefrólogo & Experto clínico & $\begin{array}{l}\text { Asociación Colombiana de Nefrología } \\
\text { e Hipertensión Arterial / Universidad de Caldas }\end{array}$ \\
\hline Gustavo Aroca Martínez & $\begin{array}{l}\text { Médico, internista nefrólogo, PhD. en } \\
\text { Educación e Investigación }\end{array}$ & Experto clínico & $\begin{array}{l}\text { Asociación Colombiana de Nefrología } \\
\text { e Hipertensión Arterial / Universidad Simón Bolívar }\end{array}$ \\
\hline Kelly Rocío Chacón Acevedo & $\begin{array}{l}\text { Fisioterapeuta, MSc. en Epidemiologia } \\
\text { Clínica }\end{array}$ & Epidemióloga & $\begin{array}{l}\text { Universidad Nacional de Colombia / Asociación } \\
\text { Colombiana de Nefrología e Hipertensión Arterial / } \\
\text { Instituto Global de Excelencia Clínica, } \\
\text { Keralty Colombia }\end{array}$ \\
\hline María Paula Gutiérrez Sepúlveda & $\begin{array}{l}\text { Nutricionista dietista, MSc. en Epidemiologia } \\
\text { Clínica }\end{array}$ & Epidemióloga & $\begin{array}{l}\text { Instituto Global de Excelencia Clínica, } \\
\text { Keralty Colombia }\end{array}$ \\
\hline
\end{tabular}

Fuente: elaboración propia.

\section{Preguntas clínicas}

El grupo desarrollador definió las preguntas de interés y se categorizaron en función del aspecto clínico abordado en el diagnóstico y el tratamiento. Las preguntas formuladas se presentan en el anexo A.

\section{Búsqueda de la evidencia}

La búsqueda de la evidencia se realizó a través de una revisión sistemática (RS) de la literatura. Las consultas en función de la fuente se detallan en el siguiente apartado. 


\section{Fuentes de información}

Para la identificación de evidencia a través de bases de datos electrónicas se realizó una búsqueda sistemática en Pubmed y Embase, restringida a los últimos cinco años, teniendo en cuenta la recomendación de expertos clínicos debido al volumen de información disponible, la producción de evidencia en la temática definida y la aparición de nuevas modalidades terapéuticas.

La estrategia de búsqueda fue diseñada mediante la combinación de vocabulario controlado (de acuerdo con la condición a trabajar y los términos libres), operadores booleanos, de truncamiento y de proximidad. Se incluyó el filtro de fecha para buscar GPC, revisiones sistemáticas (RSL) y estudios primarios desde el año 2015 hasta la actualidad. La estrategia de búsqueda se encuentra en el anexo B.

Se consultaron también bases de datos de organismos desarrolladores y compiladores de GPC desde el año 2015 hasta la actualidad, se incluyen: National Institute for Health and Clinical Excellence (NICE), Guidelines

\section{Se realizó una búsqueda sistemática en Pubmed y Embase} International Network (GIN), Ministerio de Salud de Colombia, Ministerio de Salud de Chile, Ministerio de Salud de Qatar, Ministerio de Salud de España (GuíaSalud), Scottish Intercollegiate Guidelines Network (SIGN) y Cenetec.

Adicionalmente, se realizó una búsqueda de evidencia en motores de búsqueda genéricos como Google y Google Scholar, y se consultó a los expertos clínicos sobre bibliografía que no haya sido encontrada en el proceso de búsqueda.

\section{Tamización y selección de la evidencia}

Se realizó la tamización por título y resumen de la información de manera independiente por dos revisores: experto clínico y metodólogo, en búsqueda de evidencia orientada específicamente al diagnóstico o tratamiento de AMOM-ERC, también las GPC de ERC con apartado de alteraciones del metabolismo óseo mineral fueron consideradas. En caso de desacuerdos, estos fueron resueltos mediante consenso entre los revisores.

Los documentos preseleccionados en la tamización fueron revisados a texto completo y acordados en consenso por los integrantes del equipo clínico y metodológico. Los documentos 
fueron incluidos solo si cumplían los siguientes criterios (el diagrama de flujo de selección de la evidencia se encuentra en el anexo C):

1. Tipo de estudio: GPC basada en evidencia, RSL, ensayos clínicos o estudios observacionales.

2. Población o condición: pacientes adultos (18 años o más) con ERC y diagnóstico o sospecha de alteraciones del metabolismo óseo mineral.

3. Aspecto clínico abordado: diagnóstico y tratamiento.

4. Publicación: entre 2015 y 2020.

5. Idioma: inglés y español.

\section{Evaluación de la calidad de la evidencia}

Para los documentos incluidos que cumplieron los criterios definidos previamente, se realizó la calificación de la calidad de la evidencia considerando herramientas válidas por cada tipo de estudio, tales como Agree II para GPC, Amstar-2 para RSL, RoB para ensayos clínicos y Newcastle Otawa para estudios observacionales (cohortes o casos y controles) y herramienta Joanna Briggs Institute para series de casos o reportes de caso, este proceso se realizó de manera independiente por parte de dos evaluadores del equipo metodológico (anexo D).

\section{Recomendaciones preliminares}

A partir de la información recolectada, se realizó síntesis narrativa por cada pregunta y se plantearon las recomendaciones preliminares al considerar la posibilidad de implementación de las recomendaciones en el país.

\section{Consenso formal de expertos}

A través de la metodología Delphi modificado, se llevó a cabo el consenso de expertos. Todos los participantes declararon sobre el conflicto de interés. El grupo de gestión de conocimiento de Asocolnef analizó el conflicto declarado y su potencial efecto en las respuestas emitidas para garantizar la transparencia del consenso.

Se definió un acuerdo cuando la recomendación alcanzó una votación de al menos un $80 \%$ a favor, considerando como denominador para cada recomendación el número total de participantes en la votación por ítem. 
Inicialmente se realizó una consulta preconsenso para identificar las recomendaciones que requerían una sesión de consenso virtual. Esta consulta se realizó entre el 12 y 16 de febrero del 2021 y contó con la participación de 50 expertos diferentes al grupo desarrollador, como resultado de este proceso hubo cuatro recomendaciones que no alcanzaron el umbral del $80 \%$.

Así, la sesión virtual de consenso se realizó el día 02 de marzo del 2021 a través de la plataforma Zoom. Se presentaron las recomendaciones no aprobadas en la consulta preconsenso y las nuevas recomendaciones, considerando las observaciones de los expertos consignadas en la consulta inicial. Fueron necesarias dos rondas de discusión y votación hasta lograr el acuerdo.

\section{Graduación de recomendaciones}

El grupo desarrollador clasificó las recomendaciones según la dirección y la fuerza, dando lugar a recomendaciones a favor o en contra y entre fuertes o débiles, considerando la calidad de evidencia, el balance de riesgos y beneficios, el consumo de recursos, la disponibilidad en el contexto y las observaciones emitidas por el colectivo experto.

\section{Resultados de la RS}

En total se incluyeron 30 documentos, de los cuales siete fueron GPC, 11 RSL, siete ensayos clínicos, cuatro estudios observacionales (cohortes) y un estudio de prueba diagnóstica.

Seis de las GPC superaron el umbral del60\% en los dominios 3 y 6 de Agree II; para las RSL la calificación fue críticamente baja para nueve, baja para una y alta para una; en relación con los ensayos clínicos y los estudios observacionales la calidad fue baja. El proceso de selección de la evidencia se encuentra en el anexo C y la calificación de esta en el anexo D.

\section{Diagnóstico}

1. ¿Cuándo está indicada la realización de estudios de laboratorios exploratorios de alteraciones bioquímicas de AMOM-ERC?

De la evidencia recolectada, cinco GPC $[13,17]$ tenían recomendaciones orientadas a esta pregunta. Tres de las guías $[13,14,17]$ incluidas coinciden en recomendar la monitorización de calcio, fósforo, fosfatasa alcalina (FA) y PTH como marcadores diagnósticos de alteraciones bioquímicas de AMOM-ERC. Respecto al momento de inicio de estas mediciones, se ha propuesto empezar la tamización a partir del estadio G3a de la ERC $[13,14,17]$, o tasa de 
filtración glomerular (TFG) menor a $45 \mathrm{ml} / \mathrm{min} / 1.73 \mathrm{~m}^{2}$ [16]. Vale la pena señalar que la guía de NICE15 en su momento sugirió evitar la medición rutinaria de calcio, fósforo, PTH y vitamina $\mathrm{D}$ en pacientes con TFG de $30 \mathrm{ml} / \mathrm{min} / 1,73 \mathrm{~m}^{2}$ o superior.

Al tener en cuenta la variabilidad del comportamiento de los biomarcadores de interés en función del estadio de la ERC, las guías incluidas consideraron la utilidad de medición de cada biomarcador dependiendo del estadio de enfermedad, la magnitud de las alteraciones y la progresión de la ERC para formular su frecuencia de monitorización13,14,16. De esta manera, para los estadios G3a y G3b se ha comorbilidades que contribuyen al propuesto la medición de calcio y fósforo sérico semestral o anual, mientras que para

Mayormente en pacientes con aumento del riesgo cardiovascular la PTH las mediciones repetidas serán de acuerdo al nivel basal y la progresión de la ERC. Para el estadio G4 la medición de calcio y fósforo se propuso en una medición trimestral o semestral y la de PTH semestral o anual; finalmente, para el estadio G5 se ha propuesto la medición de calcio y fosfato de uno a tres meses y para PTH de tres a seis meses.

La FA se ha descrito como frecuencia de monitorización anual o más frecuente ante la PTH elevada $[13,14,16]$. Para la FA, la guía de Malasia ha sugerido medición de seis a doce meses en estadio 3 de la ERC, de tres a seis meses en estadio 4 y cada tres meses (o menos) en estadio 5 sin requerimiento de diálisis [16].

Respecto a la medición de 25 hidroxivitamina D $(25(\mathrm{OH}) \mathrm{D})$ o calcidiol, se sugirió la medición a partir del estadio G3a y hasta G5D considerando la frecuencia de repetición en función de niveles basales e intervenciones [13,14,17]. También se ha propuesto la búsqueda de acidosis metabólica en pacientes con ERC en estadios de G3 a G5 [5].

Parece importante que los médicos conozcan los métodos o las técnicas de análisis empleadas en el laboratorio y los aspectos relacionadas con las muestras para facilitar la comprensión de resultados, en este sentido, la guía china basada en Kdigo propuso que los laboratorios reporten dicha información (1B) [13].

Al tener en cuenta la fisiopatogenia de las AMOM-ERC, estas inician desde las etapas tempranas de la ERC, se ha planteado una exploración en búsqueda de alteraciones bioquímicas desde los estadios 1 y 2 de la ERC, mayormente en pacientes con comorbilidades que 
contribuyen al aumento del riesgo cardiovascular.

\section{Recomendaciones}

- Realizar estudios de laboratorios exploratorios de alteraciones bioquímicas de AMOMERC, incluyendo calcio sérico, fósforo sérico, $\mathrm{PHT}, 25 \mathrm{OH}$ vitamina $\mathrm{D}$, bicarbonato (HC03) y FA a partir del estadio G3a de la ERC.

\section{Fuerte a favor}

- Realizar mediciones de calcio, fósforo y FA en suero en función del estadio de la ERC, de manera que para estadios G3a y G3b se realice de manera semestral o anual, en estadio G4 se realice cada tres meses y máximo cada seis meses y para el estudio G5 se realice mensual o trimestral, de acuerdo con el juicio clínico.

\section{Fuerte a favor}

- Realizar un estudio exploratorio de PTH para estadios G3a y G3b, de acuerdo con los niveles de referencia y la progresión de la enfermedad. Para el estadio G4 se recomienda medición semestral o anual y en estadio G5 una medición cada tres meses y máximo cada seis meses.

\section{Fuerte a favor}

- Considerar los niveles basales de $25 \mathrm{OH}$ vitamina D y las intervenciones para determinar la frecuencia de medición de este biomarcador en pacientes con ERC.

\section{Fuerte a favor}

- Considerar los niveles de referencia del HCO3- y la progresión de la enfermedad en la definición de la frecuencia de medición de este biomarcador en pacientes con ERC.

\section{Débil a favor}

- Considerar las mediciones anuales de calcio, fósforo y PTH desde estadios tempranos de ERC (G1 y G2), dados su papeles como factores de riesgo y marcadores de enfermedad cardiovascular y ósea, como parte de la evaluación clínica integral del paciente.

\section{Opinión de expertos}

- Se sugieren mediciones de biomarcadores en pacientes en prediálisis y diálisis con hallazgos de alteraciones, entre uno y seis meses, de acuerdo con la necesidad clínica del paciente.

\section{Opinión de expertos}




\section{2. ¿Cuáles son los métodos diagnósticos alternativos a la biopsia de hueso, recomen- dados para la detección de alteraciones óseas en pacientes con AMOM-ERC?}

A pesar de que la biopsia ósea ha sido considerada como el estándar de oro en el diagnóstico de alteraciones óseas en pacientes con AMOM-ERC, en China se ha sugerido su uso en casos definidos: fractura, dolor óseo persistente, hipercalcemia e hipofosfatemia inexplicable, toxicidad por aluminio y antes del uso de bisfosfonato para el tratamiento de la AMOM-ERC [13].

Ante las limitaciones en la implementación de esta herramienta diagnóstica en diferentes contextos, tres de las GPC incluidas propusieron métodos alternativos para la identificación de estas condiciones. Algunas han sugerido el uso de niveles de PTH sérica o de FA o fosfatasa alcalina específica de hueso como indicadores de recambio óseo en pacientes con ERC en estadios entre G3a y G5, considerando la disponibilidad en el contexto (2B) [13,14]. Otras alternativas propuestas consisten en la detección de marcadores del colágeno, derivados del hueso [13] y la determinación de la densidad mineral ósea (DMO) [17]. Investigaciones recien-

\section{Se encontró una asociación entre alto recambio óseo y altos niveles séricos de dimetilsulfona}

tes han sugerido nuevos biomarcadores para identificar alteraciones óseas en pacientes con ERC. Al respecto, en 2019, De Maré et al. [18] encontraron que la esclerostina circulante y la expresión ósea de esclerotina tuvieron una correlación significativa moderada y ambas

se correlacionaron negativamente con parámetros histomorfométricos óseos y biomarcadores séricos de formación y recambio óseo; estos autores concluyeron que la esclerostina circulante puede ser un marcador de relevancia clínica de alteraciones óseas, aunque estos hallazgos deberían ser confirmados en estudios grandes y controlados.

Por su parte, en 2019, Druck et al. [19] revisaron la relación entre la osteopontina (un importante regulador de la mineralización ósea) y las alteraciones bioquímicas (fósforo, calcio, FA y hormona paratiroidea intacta (PTHi)) en una cohorte de pacientes con ERC en estadio 5 en hemodiálisis, encontrando que la osteopontina se correlaciona positivamente con la PTHi (rho: 0,56, p < 0,0001), por lo que puede ser útil su medición en el seguimiento de pacientes con alteraciones óseas.

En el mismo sentido, en 2016, Sprague et al. [20] realizaron un estudio de prueba diagnóstica para determinar el valor predictivo de los niveles séricos de PTHi, PTH total, fosfatasa alcalina específica para hueso y propéptido amino-terminal del procolágeno tipo 1 
(P1NP) y la evaluación histomorfométrica del recambio óseo en pacientes en hemodiálisis de Brasil, Portugal y Venezuela. El estudio incluyó 492 participantes, encontrando que los biomarcadores PTHi, PTH total y fosfatasa alcalina específica de hueso discriminan entre tasa de recambio óseo bajo y no bajo; además, la PTHi y la fosfatasa alcalina específica del hueso discrimina entre la tasa de recambio óseo alta y no alta.

De la misma manera, en 2020 Aaltonen et al. [21] evaluaron la tomografía por emisión de positrón con flúor 18 (18F-Na PET) y la biopsia ósea en 21 pacientes en diálisis. Los autores encontraron una correlación entre las pruebas diagnósticas en pacientes con bajo recambio óseo, sugiriendo su utilidad en el diagnóstico de enfermedad ósea de bajo recambio sin recurrir a la biopsia de hueso; sin embargo, no hubo suficientes pacientes para evaluar resultados en pacientes con enfermedad ósea de alto recambio.

A su vez, en 2020, Baptista et al. [22] evaluaron la asociación entre metabolitos séricos y la clasificación de TMV del hueso (recambio óseo, mineralización y volumen) en 46 pacientes de Brasil con ERC en estadio 5 en tratamiento de hemodiálisis, mediante el uso de espectroscopia de resonancia magnética nuclear (una técnica de química analítica) y biopsia ósea. Se encontró una asociación entre alto recambio óseo y altos niveles séricos de dimetilsulfona, glicina, citrato y $\mathrm{N}$-acetilornitina, mineralización anormal con bajos niveles séricos de etanol y volumen bajo con bajos niveles de carnitina; sin embargo, estos hallazgos son preliminares o de fases primarias de investigación, por lo que su interpretación debe ser cautelosa, al menos hasta que la información sea confirmada en estudios con muestras más grandes y controladas.

\section{Recomendaciones}

- A pesar de la ausencia de sitios donde se procesen biopsias de hueso en Colombia, se sugiere promover medidas académicas y políticas públicas para la investigación y el desarrollo de esta prueba diagnóstica por parte de patólogos expertos en el país.

\section{Opinión de expertos}

- Considerar el uso de biomarcadores (calcio, fósforo, fosfatasa alcalina, 25(OH)D y PTH) y el juicio clínico para el diagnóstico de AMOM-ERC.

\section{Fuerte a favor}

\section{3. ¿Cuál es el método recomendado para el diagnóstico de calcificación vascular?}

Con el interés de explorar calcificaciones ectópicas en pacientes con ERC, tres guías incluidas $[13,14,17]$ sugieren, dentro de los métodos diagnósticos de calcificación vascular, la 
radiografía lateral de abdomen (índice de Kauppila) y la radiografía postero-anterior de manos y pelvis (índice de Adragao); la ecocardiografía para la detección de calcificaciones valvulares y la tomografía de tórax por haz de electrones y la tomografía de tórax computarizada de cortes múltiples (2C) para el diagnóstico de calcificaciones coronarias.

La propensión o la tendencia a la calcificación en el suero se puede medir con la prueba de inhibición de calcificación (T50), la cual cuantifica la velocidad en que las partículas de calciproteínas primarias se convierten en partículas de calciproteínas secundarias, las cuales están relacionadas con la etiología de la calcificación vascular; entre menor el T50, mayor tendencia a la calcificación.

En el ensayo clínico desarrollado en 2019 por Aigner et al. [23], con el objetivo de evaluar el efecto a largo plazo de la suplementación con bicarbonato de sodio oral en pacientes con ERC de estadios de 3 al 4 y acidosis metabólica crónica sobre la tendencia a calcificación en el suero, los investigadores emplearon la prueba T50. No hubo diferencias estadísticas en el T50 basal ni después de cuatro semanas entre el grupo de intervención con bicarbonato y el grupo control.

En la cohorte de pacientes descrita en 2016 por Chen et al. [24], se investigó la asociación entre la densidad ósea vertebral (VBD) y la calcificación arterial coronaria, por medio de tomografía de tórax computarizada (TC) y con la DMO. Se encontró una asociación entre VBD y DMO. La VBD baja en comparación con la DMO baja tuvo una más fuerte asociación con índices más altos de calcificación coronaria y mortalidad.

En el mismo año, este autor lideró una investigación para conocer las asociaciones entre la DMO en diferentes localizaciones esqueléticas, la calcificación de arterias

Se encontró una asociación entre VBD y DMO coronarias determinada por TC y la extensión de la calcificación vascular, medida histológicamente en biopsias vasculares obtenidas en pacientes llevados a trasplante renal con donante vivo. En el modelo multivariable se encontró una asociación entre DMO baja y la presencia de calcificación vascular extensa y mayor índice de calcificación de arterias coronarias [25].

\section{Recomendaciones}

- Considerar la realización de radiografía lateral de abdomen (índice de Kauppila), posteroanterior de manos y pelvis (índice de Adragao) para la detección de calcificaciones 
vasculares.

\section{Fuerte a favor}

- Realizar ecocardiografía en pacientes con ERC en estadios G3-G5 para detectar calcificaciones valvulares.

\section{Débil a favor}

- Realizar tomografía computarizada de tórax de cortes múltiples para la detección de calcificaciones en las arterias coronarias, considerando la disponibilidad de la tecnología y el juicio clínico.

Fuerte a favor

\section{4. ¿Cómo se realiza el diagnóstico de alteraciones del metabolismo óseo en pacientes con trasplante renal?}

Desde el momento de la evaluación pretrasplante se ha propuesto la medición de PTH sérica en búsqueda de alteraciones de metabolismo óseo [26], sin embargo, en el periodo posoperatorio, el seguimiento de biomarcadores toma aún mayor relevancia al tener en cuenta que una cifra importante de pacientes trasplantados podría presentar AMOM-ERC.

Ante esta situación, las guías $[13,14]$ han sugerido la medición de calcio y fósforo en suero para el diagnóstico de AMOM-ERC. La frecuencia de medición varía en función del momento desde el trasplante, la magnitud de alteraciones y la progresión de la ERC. Durante el periodo inmediatamente posterior al trasplante renal, las guías han propuesto una medición semanal de niveles de calcio y fósforo en suero hasta la estabilización de las cifras (1B) [13]. Mientras que para el periodo posterior a la fase inmediata, el seguimiento de calcio, fósforo y PTH considera además el estadio de la ERC, de tal manera que para estadio de G1 a Gb3T la medición de calcio y fósforo en suero sea una o dos veces por año, mientras que para la PTH sea una vez al año; para el estadio G4T, el calcio y el fósforo de dos a cuatro veces al año y la PTH entre una y dos veces al año. En el estadio G5T, la frecuencia de medición del calcio y el fósforo podría oscilar entre cuatro y doce veces al año y el de la PTH entre dos y cuatro veces. La medición de FA se sugiere a partir del estadio G3aT hasta el G5T, anualmente o bajo juicio clínico según el nivel de PTH [14].

\section{Recomendaciones}

- En el periodo postrasplante inmediato, se sugiere una medición de calcio y fósforo para el diagnóstico de AMOM-ERC.

Fuerte a favor 
- En el periodo postrasplante inmediato, se sugiere medición semanal de calcio y fósforo en suero hasta niveles razonables.

\section{Débil a favor}

- Se recomienda una medición de calcio y fósforo semestral o anual, así como una medición anual de PTH en estadios de G1 a Gb3T en fase de postrasplante tardío.

\section{Fuerte a favor}

- En estadio G4T, se sugiere medición de calcio y fósforo bimestral y máximo semestral, mientras que mediciones de PTH entre una y dos veces al año.

\section{Fuerte a favor}

- Se sugiere seguimiento de calcio y fósforo mensual o trimestral en el estadio 5GT y para PTH que sea trimestral o semestral.

\section{Fuerte a favor}

- Se sugiere medición de FA a partir del estadio G3aT al G5T, anualmente o con mayor frecuencia según juicio clínico y nivel de PTH.

\section{Fuerte a favor}

\section{Tratamiento}

\section{5. ¿Cuándo realizar intervención nutricional en relación con el aporte de micronu- trientes (calcio y fósforo) en pacientes con AMOM-ERC?}

Cuatro GPC $[13,14,17,27]$ propusieron recomendaciones para esta pregunta. Respecto al fósforo, se ha sugerido reducir su consumo dietario entre 800 y $1000 \mathrm{mg} /$ día en pacientes con ERC en estadios de G3a a G5D, dependiendo el valor objetivo (2D) [13,14], acompañado de seguimiento nutricional [17], al tiempo que se ha promovido la restricción en consumo de proteína y alimentos con aditivos que contienen fosfato [13,14]. En pacientes con trasplante renal e hipofosfatemia se sugirió la reposición de fosfato a través de dieta o suplementos [27].

Respecto a la ingesta de calcio, las guías proponen una ingesta total de entre 800 y 1.000 $\mathrm{mg} /$ días, incluyendo el proveniente de la dieta, los suplementos y los quelantes de fosfato con contenido de calcio, para pacientes con ERC en estadios 3 y 4 que no reciben tratamiento con análogos de vitamina D. Mientras que para pacientes con ERC en estadio 5D se ha sugerido considerar el uso concomitante de calcimiméticos, suplementos de calcio y vitamina D para el ajuste del consumo de calcio en la dieta. En todo caso, habrá que considerar el consumo excesivo de calcio y análogos de vitamina D por el riesgo de calcificación vascular [27]. 


\section{Recomendaciones}

- Reducir el consumo de fósforo dietario entre 800 y $1000 \mathrm{mg} /$ día en pacientes con ERC en estadios de G3a a G5D, aún con niveles normales de fósforo sérico.

\section{Fuerte a favor}

- Se sugiere que pacientes con AMOM-ERC reciban asesoría y seguimiento nutricional. Fuerte a favor

- Restringir el consumo de proteínas y alimentos, fórmulas, preparados con aditivos que contienen fosfato (conservantes, bebidas azucaradas, enlatados, etc.), considerando cada caso de manera individualizada $[13,14]$.

\section{Fuerte a favor}

- Se sugiere suplementación de fosfato en pacientes con trasplante renal e hipofosfatemia a través de dieta o suplementos [27].

\section{Débil a favor}

- Para los pacientes en diálisis, considerar el contenido de fósforo en medicamentos de consumo crónico, especialmente antihipertensivos (amlodipino, lisinopril, irbesartán, metoprolol).

\section{Opinión de expertos}

\section{6. ¿Cuál es la indicación de suplementación con vitamina D en pacientes con AMOM- ERC?}

Cuatro guías [14, 15, 17, 27] respondieron esta pregunta. La guía Kdigo recomendó que ante la deficiencia o insuficiencia de vitamina D se apliquen las estrategias empleadas en la población general [14].

En pacientes con ERC en estadios del 1 al 5 y en postrasplante se sugirió la suplementación de vitamina $\mathrm{D}$ en forma de colecalciferol o ergocalciferol para tratar la deficiencia de esta vitamina [14]. Kdoqi, NICE y la GPC ecuatoriana no recomiendan la suplementación rutinaria de vitamina D como estrategias de tratamiento para AMOM-ERC [15, 17,27].

En el análisis secundario de 117 participantes del ensayo clínico en 2018 de Yadav et al., el cual originalmente incluyó pacientes adultos con ERC con tasa de filtración glomerular entre 15 y $45 \mathrm{ml} / \mathrm{min} / 1,73 \mathrm{~m}^{2}$, el objetivo principal fue evaluar el efecto de la suplementación con vitamina D (colecalciferol) sobre el cambio del flujo en arteria braquial, la rigidez arterial, los 
niveles de vitamina D y otros biomarcadores. Se encontró que, a la semana 16, el cambio en los niveles de 25-hidroxi (OH) vitamina D en el grupo de colecalciferol fue de $24,91 \mathrm{ng} / \mathrm{ml}$ (IC $95 \% 21,77$ a 28,06) y en el grupo placebo $1,51 \mathrm{ng} / \mathrm{mL}$ (IC $94 \%,-0.46$ a 3,48 ng/mL). Además, se encontró una disminución en los niveles de PTHi de 53,37 pg/ml (IC 95 \% -82,37 a -24,36) en el grupo con suplementación, mientras que en el grupo placebo no hubo cambios. Vale la pena mencionar que en el análisis por subgrupos, acerca del cambio de niveles de PHTi, se encontró que el grupo de individuos mayores de 50 años tienen menores reducciones de la PTHi comparados con los menores de esta edad. Estos hallazgos deben ser analizados con cautela al tener en cuenta que provienen de un análisis secundario, para el cual no fue diseñado el estudio original y en el análisis estadístico descrito aparentemente no se realizaron ajustes de comparaciones múltiples [28].

\section{Recomendaciones}

- Se sugiere la prescripción y el uso de colecalciferol o ergocalciferol para tratar la deficiencia de vitamina D en pacientes con AMOM-ERC.

\section{Fuerte a favor}

- Se sugiere la prescripción de vitamina D en pacientes con insuficiencia y niveles de PTH persistentemente elevados.

\section{Opinión de expertos}

\section{7. ¿Cuál quelante intestinal del fósforo utilizar para el manejo de la hiperfosfatemia en AMOM-ERC?}

Siete documentos $[13,14,16,17,29-31]$, cuatro GPC y tres RSL, dieron respuesta a esta pregunta. El uso de quelantes de fósforo es una alternativa de manejo de la hiperfosfatemia, considerando el estadio de la ERC (1B) [17]; sin embargo, algunas guías consideran que su prescripción, cuando son a base de calcio (2B) o de aluminio (1C) para pacientes con ERC en estadios de G3a a G5D, debe ser evitada $[13,14,17]$ o reducida hasta $1.500 \mathrm{mg}$ de calcio elemental por día (2B).

Ante hipercalcemia persistente o recurrente, calcificaciones vasculares, niveles de PTHi bajos, la alternativa propuesta son los quelantes de fósforo no cálcicos [17], en los casos donde no se logra la corrección a través de estrategias nutricionales [16]; sin embargo, se hace hincapié a la individualización de este tipo de tratamiento [14]. 
En la RS del 2018, de Ruospo et al. [29], se evaluó la efectividad y la seguridad de quelantes de fosfato (sevelamer, lantano, hierro, quelantes basados en calcio, bixalomer, nicotinamida y colestilan) contra placebo, cuidado usual y entre quelantes de fosfato sobre la reducción de fosfato en suero.

En total se incluyeron 104 estudios entre ensayos clínicos aleatorizados y cuasiensayos clínicos, los cuales reunieron un total de 13.744 participantes. Los estudios primarios consideraron participantes con ERC desde estadio G2 hasta G5D, con requerimientos de hemodiálisis o diálisis peritoneal. El riesgo de sesgo de los estudios fue variable.

Como resultado de la revisión no se encontraron diferencias al comparar los quelantes de fósforo con placebo o cuidado estándar en los desenlaces de efectividad (muerte, infarto de miocardio, accidente cerebrovascular, fosfato, calcio, FA y bicarbonato en suero, hipercalcemia y tasa de filtración glomerular). Mientras que, al comparar entre quelantes, los hallazgos de la revisión indican que en pacientes en estadio G5D ,el sevelamer redujo el riesgo de desarrollar hipercalcemia en $70 \%$ (RR: 0,30 IC $95 \% 0,20$ - 0,43, I2: 49,47\%, certeza de la

\section{Los niveles de calcio no son} corregidos por los niveles de albúmina sérica en la práctica clínica evidencia baja) en comparación con quelantes a base de calcio y también redujo el riesgo de muerte en $47 \%$ (RR 0,53 IC $95 \%$ 0,30 - 0,91, certeza de la evidencia baja) respecto al mismo comparador. En relación con la seguridad, se presentaron eventos gastrointestinales en pacientes con ERC en estadios de G2 a G5 asociados al uso de quelantes de fósforo. No fue estimable el efecto de los quelantes sobre el nivel de fosfato en suero.

En la RS del 2016 de Sekercioglu et al. [30], se comparó el efecto de quelantes de fósforo sobre desenlaces importantes para el paciente con ERC. A través de un metaanálisis en red, se encontró mayor mortalidad con quelantes basados en calcio comparado con sevelamer (RR: 1,89 IC $95 \%$ 1,02 - 3,50, evidencia de calidad moderada). En el metaanálisis clásico no se encontraron diferencias sobre los desenlaces [30]. En otra RS del 2017 del mismo autor [31], tampoco hubo diferencias entre estrategias de reducción del fosfato.

Finalmente, un estudio de cohorte que incluyó a 521 pacientes del ensayo Contrast, analizó el papel del ensayo de albúmina en los niveles de calcio, para la prescripción de quelantes de calcio, en pacientes con ERC y alteraciones del metabolismo óseo mineral en diálisis. A partir de los análisis realizados, los investigadores encontraron que independientemente 
del método utilizado para la medición de la albúmina (verde de bromocresol o púrpura de bromocresol), los niveles de calcio $(2,32 \pm 0,18$ y $2,34 \pm 0,17 \mathrm{mmol} / \mathrm{L}[\mathrm{p}=0,26])$ y la frecuencia de prescripción de quelantes de fosfato basados en calcio eran similares (51\% vs $45 \%$ ), por lo tanto, los autores concluyeron que los niveles de calcio no son corregidos por los niveles de albúmina sérica en la práctica clínica cuando se considera la prescripción de quelantes de fósforo libres o basados en calcio en pacientes con diálisis [32].

\section{Recomendaciones}

- Se sugiere que la prescripción y el uso de quelantes de fósforo sea individualizado, al considerar las características del paciente, el estadio de la ERC y el tipo de quelante.

\section{Fuerte a favor}

- Se sugiere el uso de quelantes de fósforo no cálcico, disponibles en Colombia, en casos de hipercalcemia persistente o recurrente, calcificaciones vasculares y niveles de PTHi bajos.

\section{Fuerte a favor}

- Evitar el uso rutinario de quelantes de fósforo a base de calcio para pacientes con ERC en estadios de G3a a G5D, considerando el contexto del paciente.

\section{Fuerte en contra}

- Considerar el uso de quelantes de fósforo a base de aluminio por periodos inferiores a tres meses, en aquellos pacientes donde fallaron las medidas no farmacológicas y los niveles de fosfato se encuentren fuera de metas establecidas para el estadio de la ERC.

\section{Opinión de expertos}

- Para pacientes en diálisis, se sugiere el uso de quelantes de fósforo tipo sevelamer y en pacientes en prediálisis considerar seleccionar el clorhidrato o el carbonato de sevelamer, de acuerdo con el estado ácido-base.

\section{Opinión de expertos}

\section{8. ¿Cuál es la indicación de los medicamentos bloqueadores de la absorción intestinal de fósforo?}

En la RS del 2018 de Ruospo et al. [29] se evaluó la efectividad y la seguridad de quelantes de fosfato (sevelamer, lantano, hierro, calcio, bixalomer, nicotinamida y colestilan) contra placebo, cuidado usual y entre quelantes de fosfato sobre la reducción de fosfato en suero. Se incluyeron participantes con ERC desde estadio G2 hasta G5D con requerimientos de hemodiálisis o diálisis peritoneal. Entre varias comparaciones se realizó la correspondiente 
a nicotinamida con placebo o cuidado usual, sin encontrar diferencias significativas en mortalidad (RR: 2,83 IC $95 \%$ 0,12 - 64,89) y nivel de fosfato en suero (DM: -0,56 IC $95 \%-1,24$ $0,12)$.

El ensayo clínico del 2017 de Block et al. [33] evaluó la eficacia y la seguridad a corto plazo de seis brazos de tenapanor contra placebo durante cuatro semanas. Se incluyeron pacientes con hiperfosfatemia y en terapia de hemodiálisis de mantenimiento $(\mathrm{N}=162)$. Se realizó lavado de tres semanas para quelantes de fósforo y se verificó nuevamente la elegibilidad antes de iniciar las intervenciones. Se reportó una reducción promedio entre 0,47 y 1,98 $\mathrm{mg} / \mathrm{dl}$ en los grupos de intervención, mientras que en el grupo placebo fue de $0,54 \mathrm{mg} / \mathrm{dl}$. Los mayores cambios se registraron para los grupos con tenapanor de 10 y $30 \mathrm{mg}$ dos veces al día. Entre el 9 y el $43 \%$ de los participantes asignados a intervención alcanzaron meta de fosfato de $5,5 \mathrm{mg} / \mathrm{dl}$, comparado con el $8 \%$ de los participantes del grupo control. Los eventos adversos fueron más frecuentes en los grupos de intervención (57 - 76\%) excepto en el brazo de $1 \mathrm{mg}$ dos veces por semana. Hubo un evento fatal por insuficiencia cardiaca 23 días después de la última dosis de la terapia. Los eventos adversos gastrointestinales fueron los más comunes y en algunos casos implicaron la discontinuación de la intervención.

Por otra parte, en el ensayo clínico aleatorizado, doble ciego, fase III del 2019 de Block et al. [34] se evaluó la eficacia y la seguridad del tenapanor en 152 pacientes con ERC estadio 5 , en terapia de hemodiálisis crónica, con tres o más dosis de quelantes de fosfato y niveles de fosfato sérico de cuatro a siete $\mathrm{mg} / \mathrm{dl}$, quienes recibieron tenapanor de 3, 10 o $30 \mathrm{mg}$ al día por vía oral durante ocho semanas y, al final de este periodo, se aleatorizaron nuevamente en grupos para continuar con la misma dosificación o recibir placebo durante cuatro semanas (periodo de interrupción de la terapia).

Los hallazgos reportan una reducción de fosfato en el suero para los grupos de intervención al final de ocho semanas. En el grupo con dosis de tres $\mathrm{mg}$ se redujo el fosfato sérico en promedio 1,00 (DE: 1,73) mg/dl, con la dosis de $10 \mathrm{mg}$ la reducción fue de 1,02 (DE: 1,66) mg/dl y con la dosis de $30 \mathrm{mg}$ la reducción fue de 1,19 (DE: 1,82) mg/dl.

En el periodo de interrupción de la terapia, el grupo de placebo aumentó la concentración de fosfato en suero en promedio $0,85 \mathrm{mg} / \mathrm{dl}$, mientras que en los grupos de intervención agrupados el incremento fue de $0,02 \mathrm{mg} / \mathrm{dl}$, con una adherencia al fármaco superior al $92 \%$. Respecto a la seguridad del tenapanor, en los grupos que lo recibieron se presentaron síntomas gastrointestinales como heces blandas y aumento en la frecuencia de deposiciones. 
En el ensayo clínico del 2018 de Malhotra et al. [35] se evaluó el efecto de la niacina sobre niveles de fosfato sérico y otros marcadores del metabolismo mineral durante tres años en participantes con ERC, que tenían de 45 años en adelante, con enfermedad cardiovascular preestablecida (enfermedad coronaria o cerebrovascular), enfermedad vascular o arterial periférica y perfil lipídico aterogénico. No se consideraron pacientes con niveles de

\section{Respecto a la seguridad del tenapanor, en los grupos que lo recibieron se presentaron síntomas gastrointestinales} creatinina de $2,5 \mathrm{mg} / \mathrm{dl}$. Los participantes fueron asignados a simvastatina $40 \mathrm{mg}$ más niacina en dosis aumentadas semanalmente (500 a $2.000 \mathrm{mg} / \mathrm{dl}$ ) de cuatro a ocho semanas. Para los que lograron concentraciones mayores o iguales a $1.500 \mathrm{mg} / \mathrm{dl}$ se aleatorizaron a: niacina de $1.500 \mathrm{mg}$ o $2.000 \mathrm{mg}$ más simvastatina o placebo más simvastatina.

Los hallazgos reportados para 352 participantes sugieren una mayor reducción de concentración de fosfato en suero al tercer año de seguimiento en el grupo que recibió niacina respecto al grupo de placebo (3,32 versus $3,57 \mathrm{mg} / \mathrm{dl}$ ), sin cambios en el primer año de seguimiento. No se encontraron diferencias para otros marcadores de metabolismo óseo (factor de crecimiento de fibroblastos 23, calcio en suero, PTH, $25 \mathrm{OH}$ Vit D, etc.). Estos hallazgos deben ser interpretados con cuidado teniendo en cuenta el porcentaje de pérdidas al seguimiento.

\section{Recomendaciones}

- Se sugiere el uso de bloqueadores de absorción de fósforo en pacientes con ERC estadio 5 , en terapia con hemodiálisis de mantenimiento y niveles de fosfato sérico persistentemente elevados a pesar de tratamiento con quelantes de fósforo y dieta.

\section{Opinión de expertos}

\section{9. ¿Cuál es la indicación de activadores del receptor de vitamina $\mathrm{D}$ en el tratamiento de hiperparatiroidismo secundario?}

Cuatro GPC [13-15,17] incluyeron recomendaciones sobre el uso de activadores del receptor de vitamina $\mathrm{D}$ en el tratamiento de las AMOM-ERC. En pacientes con niveles de 25(OH)D apropiados y un aumento progresivo de los niveles de PTH se sugirió el tratamiento con análogos no selectivos de vitamina D o análogos selectivos de vitamina D17. El calcitriol (1,25 hidroxicolecalciferol) también se sugirió para los pacientes con AMOC-ERC y con TFG $<30 \mathrm{~mL} / \mathrm{min} / 1,73 \mathrm{~m}^{2}$ [17]. 
El uso rutinario de los activadores del receptor de vitamina D se ha desaconsejado en los pacientes en estadios del G3a al G5 sin diálisis, aunque es una alternativa de tratamiento para pacientes en estadios del G4 a G5 con hiperparatiroidismo severo y progresivo. En pacientes en estadio G5 en diálisis que requieran terapia de disminución de la PTH se propuso el uso de calcimiméticos, calcitriol, otros análogos de vitamina D o una combinación de estos [13].

Por último, la guía NICE realizada en el 2015 afirma que si la deficiencia de vitamina D ha sido corregida pero los síntomas de alteración del metabolismo óseo continúan, se puede proporcionar alfacalcidol o calcitriol para pacientes con TFG $<30 \mathrm{ml} / \mathrm{min} / \mathrm{m}^{2}$ [15].

\section{Recomendaciones}

- Se sugiere la prescripción y el uso de análogos de vitamina D en pacientes con ERC con niveles normales de vitamina D y aumento progresivo de PTH.

\section{Débil a favor}

- Se recomienda la prescripción de calcitriol en pacientes con ERC en estadios de G3a a G5 sin requerimiento de diálisis y su uso debe ser individualizado.

\section{Fuerte a favor}

- Considerar el uso de calcitriol en pacientes con ERC en estadios de G4 a G5 con hiperparatiroidismo severo y progresivo, así como en pacientes en estadio G5 de la ERC, como estrategia para controlar niveles de PTH.

\section{Débil a favor}

- Utilizar análogos selectivos de vitamina D para casos de pacientes con ERC en estadios de G3 a G5 en diálisis y calcificación vascular.

\section{Opinión de expertos}

- Considerar la elección de análogos selectivos de vitamina D sobre los no selectivos en pacientes con enfermedad cardiovascular establecida como una estrategia de prevención secundaria.

\section{Opinión de expertos}

\section{0. ¿Cuál es la indicación para el uso de calcimiméticos en AMOM-ERC?}

Dos GPC $[13,14]$ incluyeron recomendaciones sobre el uso de calcimiméticos en pacientes con AMOM-ERC. Además, cuatro RSL [36-39] incluidas evaluaron la efectividad y la seguridad de los calcimiméticos en el tratamiento de esta población. 
El uso de calcimiméticos se ha sugerido en pacientes en estadio G5 en diálisis que requieren terapia de disminución de la PTH, solos o en combinación con calcitriol u otros análogos de la vitamina D [13,15]. Una RS realizada en Canadá [36] comparó el uso de cinacalcet con el tratamiento estándar en pacientes con ERC.

Hubo una reducción de la necesidad de paratiroidectomía (RR 0,30 IC 95\% 0,22 - 0,42) mientras que no hubo diferencias en la reducción de fracturas, hospitalización por eventos cardiovasculares, mortalidad cardiovascular o por todas las causas. Los eventos adversos reportados fueron síntomas gastrointestinales de tipo náuseas (RR 2,16 IC $95 \%$ 1,46 - 3,21) y vómito (RR 2,15 IC $95 \%$ 1,66 - 2,80) y aumento de la tasa de hipocalcemia (RR: 6,0 IC 95 \% 3,65 - 9,87).

En un estudio de metaanálisis en red, donde se comparó el uso de monoterapia de vitamina D activa y cinacalcet más la vitamina D activa para el tratamiento del hiperparatiroidismo secundario, se encontró que esta última combinación no mejoró la sobrevida de los pacientes, pero sí optimizó significativamente la tasa de cumplimiento de calcio en sangre (RR: 1,82 IC $95 \%$ 1,51 - 2,21); sin embargo, la combinación aumentó la frecuencia de vómito (RR: 2,07 IC $95 \%$ 1,18 - 3,65). La monoterapia con cinacalcet aumentó el riesgo de hipocalcemia, aunque fue mayor el riesgo cuando se usó combinado con vitamina D37.

En la RS publicada en el 2018 [38] se evaluó el efecto del cinacalcet sobre la PTH sérica, el calcio, el fósforo y el producto calcio/fósforo en comparación con el tratamiento estándar. El cinacalcet redujo los niveles séricos de PTH (DMP: -206,53 pg/ml IC 95\%-264,76 a -148,3), de calcio sérico (DMP -0,73 mg/dL IC $95 \%-0,80$ a -0,66), de fosfato sérico (DMP -0,73 mg/dL IC $95 \%-0,80$ a -0,66) y el producto calcio fósforo (DMP -8,96 mg2/dL2 IC $95 \%-10,06$ a -7,87); sin embargo, estas comparaciones fueron realizadas a pesar de la presencia de un alto porcentaje de heterogeneidad entre los estudios.

El cinacalcet redujo significativamente los marcadores de resorción ósea, pero no los de formación ósea, aunque igualmente contó con un alto porcentaje de heterogeneidad entre los estudios. Por otro lado, los autores reportaron la disminución de los niveles séricos de FGF-23 en pacientes con tratamiento con cinacalcet (DMP -1.872,59 ng/L IC $95 \%-2.529,35$ a -1.215,82), aumento de la DMO con un acrecentamiento a nivel femoral pero no a nivel de la columna lumbar, así como una disminución en el riesgo de fractura y calcificación vascular. El uso del medicamento se asoció con un aumento de síntomas gastrointestinales como náuseas, vómito y diarrea, al igual que riesgo de hipocalcemia. Por último, no hubo diferencias en 
cuanto a la mortalidad cardiovascular y por todas las causas entre los grupos comparados [38].

Otra de las RSL incluidas [39] evaluó el uso de calcimiméticos en el alcance de los niveles objetivo de PTH. El etecalcide fue el agente con más probabilidad de alcanzar el objetivo de PTH en comparación con evocalcet (OR 4,93 IC $95 \% 1,33$ a 18,2) y cinacalcet (OR 2,78 IC $95 \%$ 1,19 a 6,67); sin embargo, según los análisis de los autores el etecalcide pareciera causar mayor riesgo de hipocalcemia que los comparadores, aunque el cinacalcet causa náuseas con mayor frecuencia. Esta revisión declara debilidades para hacer análisis relacionados con el riesgo de mortalidad cardiovascular y por todas las causas y fracturas, debido a la falta de seguimiento en los estudios y la heterogeneidad de estos.

\section{Recomendaciones}

- Se sugiere el uso de calcimiméticos en pacientes con ERC en estadio G5 en diálisis con niveles aumentados de PTH, en monoterapia o en combinación con análogos de la vitamina D.

\section{Débil a favor}

- Se sugiere el uso de los calcimiméticos disponibles en Colombia en casos de hiperfosfatemia o hipercalcemia persistente en pacientes con PTH elevada.

\section{Fuerte a favor}

- Considerar disminuir la dosis o adicionar suplementos de calcio en el caso de hipocalcemia persistente con el uso de calcimiméticos.

\section{Opinión de expertos}

\section{1. ¿Cuáles son las estrategias de prevención de calcifilaxis recomendadas?}

Dos GPC [16, 17] incluyeron recomendaciones sobre la prevención de calcifilaxis en pacientes con ERC. La primera de ellas sugirió evitar el desarrollo de hipercalcemia para reducir la calcificación vascular, además del uso de líquido de diálisis con concentración de calcio entre 1,25 y 1,5 mmol/L y tener precisión en las indicaciones de medicamentos que contienen calcio y análogos de vitamina D [13], mientras que la segunda aconseja evitar el uso excesivo de calcio en forma de quelantes de fósforo basados en calcio, ya que se puede asociar con un aumento en el riesgo de la calcificación vascular [16].

Adicionalmente, una cohorte de 38 pacientes (tres fueron excluidos por no tener información disponible de T50) provenientes del ensayo clínico SoBic-study que incluyó pacientes con ERC en estadios G3 y G4 con acidosis metabólica crónica (HCO3 sérico $<21 \mathrm{mmol} / \mathrm{L}$ ), para evaluar el efecto de la suplementación oral con bicarbonato sobre la tendencia a la 
calcificación en el suero, medido a través de la prueba T50 con seguimiento de cuatro semanas, comparando los niveles de HCO3- a $24 \pm 1 \mathrm{mmol} / \mathrm{L}$ (grupo de intervención) contra de $20 \pm 1 \mathrm{mmol} / \mathrm{L}$ (grupo control). Se reportó que el grupo que recibió suplementación aumentó en promedio el T50 en cuatro minutos (DE: 69) contra 18 minutos (DE: 56) en el grupo no intervenido, pero no hubo diferencias en el cambio de concentración de bicarbonato en suero según el análisis multivariado [40].

El ensayo clínico del 2015 de Floege et al. [40] tuvo como objetivos identificar los factores de riesgo de la arteriolopatía urémica calcificante y evaluar la asociación de la reducción de PTH con cinacalcet y la arteriolopatía urémica calcificante. Este ensayo incluyó participantes con hiperparatiroidismo secundario en terapia de hemodiálisis.

La intervención consistió en cinacalcet (de $30 \mathrm{mg}$ hasta $180 \mathrm{mg}$ por día) o placebo, además del tratamiento estándar durante 64 meses. Un total de 3.841 participantes fueron incluidos. 18 pacientes del grupo placebo y 6 del grupo cinacalcet desarrollaron arteriolopatía urémica calcificante. La tasa de eventos acumulada a los cuatro años fue $0,011 \%$ en los participantes del grupo placebo y de $0,05 \%$ del grupo de cinacalcet. La mediana de tiempo hasta este resultado fue de 1,3 (RIQ: 0,2 - 4,5) años entre los que recibieron placebo y de 1,8 $(0,9-3,1)$ años entre los del grupo de intervención.

Los factores de riesgo asociados a la arteriolopatía urémica calcificante, según el modelo multivariado, fueron el índice de masa corporal (HR: 1,09 IC $95 \%$ 1,05 - 1,13), la presión arterial diastólica por $10 \mathrm{~mm} \mathrm{Hg}$ (HR: 1,50 IC 95\% 1,19 - 1,90), antecedente de dislipidemia (HR: 2,15 IC $95 \%$ 0,90 - 5,15), antecedente de paratiroidectomía (HR: 5,79 IC 95\% 1,79 18,7) y ser exfumador (HR: 3,04 IC $95 \%$ 1,19 - 7,74). El sexo masculino se comportó como un factor protector, de tal manera que los hombres tienen $67 \%$ menos riesgo de presentar la condición en el periodo de seguimiento analizado respecto a las mujeres (HR: 0,33 IC La deficiencia de vitamina $\mathrm{K}$ es $95 \%$ 0,14 - 0,75). El nivel de PTH antes del frecuente en los pacientes con ERC evento de calcifilaxis fue de $796 \mathrm{pg} / \mathrm{ml}$ en el grupo placebo y de $410 \mathrm{pg} / \mathrm{ml}$ en el grupo cinacalcet.

La deficiencia de vitamina $\mathrm{K}$ es frecuente en los pacientes con ERC. La vitamina $\mathrm{K}$ juega un rol importante para activar proteínas que inhiben la calcificación vascular [41]. En los pacientes con ERC y arritmias que requieren anticoagulación es importante tener en cuenta que se aumenta el riesgo de calcificación vascular con el uso de anticoagulantes antagonistas 
de la vitamina $\mathrm{K}$.

\section{Recomendaciones}

- Prevenir la hipercalcemia y la acidosis metabólica dentro de las estrategias de prevención de calcifilaxis, además de considerar la concentración de calcio en el líquido de diálisis y los medicamentos a base de calcio como los quelantes de fósforo cálcicos y los activadores no selectivos del receptor de vitamina D.

\section{Fuerte a favor}

- Evitar la anticoagulación con antagonistas de la vitamina K en pacientes con calcificación vascular por el riesgo de calcifilaxis.

\section{Opinión de expertos}

- Evitar el uso de análogos no selectivos de vitamina D en pacientes con requerimiento de anticoagulación.

\section{Opinión de expertos}

\section{2. ¿Cuál es el tratamiento recomendado para calcifilaxis?}

En la RS del 2019 de Udomkarnjananum et al. [42] se sintetizaron el tratamiento disponible y los resultados de los pacientes que presentan calcifilaxis, a partir de 147 estudios observacionales de cohorte, series de casos y reportes de caso que incluyeron como intervención de calcifilaxis: tiosulfato de sodio, paratiroidectomía, agentes calcimiméticos, terapia de oxígeno hiperbárico y bifosfonatos. Como resultado se reportó que el 50,3\% de los pacientes recibió tiosulfato de sodio con duración promedio de la terapia de 20 semanas (DE: 26) y dosis acumulada de $1.302 \mathrm{~g}$ (DE: 2.745), $25 \%$ recibieron cinacalcet a dosis promedio de $52 \mathrm{mg}$ (DE: 31) y terapias de 27 semanas (DE: 20), al $29 \%$ se le realizó paratiroidectomía y al $15 \%$ se le suministró oxígeno hiperbárico durante 41 sesiones en promedio (DE: 24). La tasa de mortalidad fue del 46,9\% y hubo una alta frecuencia de alteraciones cutáneas.

En el metaanálisis de estudios de cohorte que agrupó a 151 pacientes con tiosulfato, no se encontraron diferencias en la mortalidad (RR: 0,89 IC $95 \%$ 0,71 - 1,12), hallazgo semejante para paratiroidectomía (RR: 0,88 IC $95 \%$ 0,69 - 1,13), cinacalcet (RR: 1,04 IC 95\% 0,75 - 1,42), oxígeno hiperbárico (RR: 0,89 IC $95 \%$ 0,71 - 1,12) y bifosfonatos (RR: 0,77 IC 95\% 0,44 - 1,32). Respecto al desenlace de seguridad, se reportó que el tiosulfato de sodio ocasionó acidosis metabólica $(32,3 \%)$, hipernatremia $(18,8 \%)$ y náuseas y vómito $(24,7 \%)$. Para la terapia de oxígeno hiperbárico se reportó barotrauma y ansiedad $(0,2 \%)$ y miopía $(0,1 \%)$. No hubo reportes para las demás alternativas de tratamiento. 
La RS del 2018 de Peng et al. [43] evaluó la eficacia y la seguridad del tiosulfato de sodio en pacientes con calcifilaxis a partir de estudios de reportes y series de caso. La revisión incluyó 45 documentos para un total de 358 pacientes. Se reportó un 84,4\% de eficacia del tiosulfato de sodio en reportes de caso y $67 \%$ en series de casos. La mortalidad posterior a la terapia fue de 26,6\% según reportes de caso y del 40,4\% según series de casos. Dentro de los eventos adversos más frecuentes se encontraron las náuseas y vómitos, sepsis y acidosis.

En el ensayo clínico fase II del 2019 de Coyne et al. [44] se evaluó la farmacocinética y la farmacodinamia del sotatercept y su efecto sobre concentraciones de hemoglobina, DMO y calcificación vascular aórtica en pacientes con ERC en hemodiálisis y anemia. Se encontró que el uso de sotatercept redujo la calcificación vascular aórtica dependiente de la dosis. Hubo eventos adversos como hipertensión, espasmo muscular, cefalea, complicación del sitio de la fístula arteriovenosa e influenza; los eventos se presentaron en ambos brazos de comparación. Estos hallazgos deben ser interpretados con cautela por ser un estudio en fases tempranas, los cuales requieren de confirmación de efectividad y seguridad en estudios fase III.

En el ensayo clínico fase II de un solo brazo del 2019 de Brandenburg et al. [45] se evaluó el efecto del SNF472 sobre la cicatrización de heridas, dolor y calidad de vida en pacientes adultos con calcifilaxis recién diagnosticada o recurrente confirmada con biopsia de piel, sin afectación cutánea 90 días previos al inicio del estudio. La intervención consistió en infusión lenta de

\section{Se encontró que el uso de} sotatercept redujo la calcificación vascular aórtica
SNF472 (400, 450, 700 o $900 \mathrm{mg})$ durante la hemodiálisis tres veces por semana durante 12 semanas, además del tratamiento estándar. En este ensayo se incluyeron 14 pacientes. Hubo pérdidas del $21 \%$ de los participantes (incluidos en análisis por protocolo). Todos

los pacientes tenían al menos una lesión de calcifilaxis y el $86 \%$ tenía una úlcera. Se encontró una mejoría promedio de la cicatrización de las heridas de 33,6 \pm 9,6 en el basal a 25,6 \pm 7,3 a la semana 12 en la herramienta de evaluación de heridas de Bates- Jensen. También disminuyó el dolor, con un cambio promedio de 71,8 $\pm 29,2 \mathrm{~mm}$ en el basal a 48,1 $\pm 28,6 \mathrm{~mm}$ a la semana 12 en la escala de dolor y la calidad de vida mejoró de 2,44 (DE: 0,89) a 1,54 (DE: 0,9).

\section{Recomendaciones}

- Se sugiere que el manejo de calcifilaxis sea individualizado, considerando las indicaciones de alternativas disponibles en el contexto y el análisis de riesgo-beneficio para el paciente. Fuerte a favor 
- Se sugieren como alternativas de tratamiento de calcifilaxis el tiosulfato de sodio, la paratiroidectomía, los calcimiméticos, la terapia de oxígeno hiperbárico y los bifosfonatos. Débil a favor

- Considerar todas las terapias disponibles en monoterapia o en combinación para el manejo de calcifilaxis.

\section{Opinión de expertos}

\section{3. ¿Cuál es la indicación de la paratiroidectomía en el manejo de AMOM-ERC?}

Tres de las GPC $[13,14,17]$ incluidas emitieron recomendaciones sobre el uso de la paratiroidectomía como tratamiento de las AMOM-ERC; asimismo, una RS [46] evaluó el impacto de la paratiroidectomía en pacientes con AMOM-ERC.

La indicación sugerida de paratiroidectomía $[13,14,17]$ se realizó para pacientes con ERC en estadios de G3 a G5 e hiperparatiroidismo severo que no hayan respondido al tratamiento. Adicionalmente, la guía realizada en China en el año 2019 [13] recomendó considerar la paratiroidectomía bajo condiciones de PTH persistentemente elevada (definida como PTHi persistentemente $>800 \mathrm{pg} / \mathrm{mL}$ ), hipercalcemia persistente con o sin hiperfosfatemia sin beneficios de la terapia instaurada, evidencia en imágenes de aumento de glándula paratiroides y la resistencia a la vitamina $\mathrm{D}$ activa o a sus análogos.

La RS del 2017 de Apetrii et al. [46] evaluó el impacto de la paratiroidectomía sobre los desenlaces de pacientes con ERC en estadio 5 e hiperparatiroidismo secundario. La revisión incluyó 15 estudios observacionales que en conjunto reunieron 24.048 pacientes prevalentes en diálisis con diagnóstico de hiperparatiroidismo secundario, sometidos a paratiroidectomía subtotal o total con o sin autotrasplante y con seguimientos entre 12 y 360 meses. Los hallazgos reportados indican una reducción de la mortalidad por todas las causas en $26 \%$ (RR: 0,74 IC $95 \%$ 0,66 - 0,83). Entre los pacientes con paratiroidectomía hubo menor mortalidad cardiovascular (RR: 0,59 IC $95 \%$ 0,46 - 0,76). Deben analizarse con precaución estos resultados al tener en cuenta la alta heterogeneidad entre los estudios (I2: $81 \%$ ).

\section{Recomendaciones}

- Se sugiere que la paratiroidectomía sea indicada en pacientes con ERC estadio G3 a G5 e hiperparatiroidismo secundario severo cuando otras alternativas de tratamiento médico conservador sean inefectivas.

Fuerte a favor 
- Considerar la paratiroidectomía como estrategia de manejo ante PTH persistentemente elevada (PTHi persistentemente $>800 \mathrm{pg} / \mathrm{mL}$ ), hipercalcemia persistente cuando otras alternativas de tratamiento médico conservador han sido inefectivas, haya aumento de la glándula paratiroides y ante la resistencia a la vitamina D activa o a sus análogos.

Débil a favor

\section{4. ¿Cuál es el tratamiento recomendado para alteraciones del metabolismo óseo en pacientes con trasplante renal?}

Dos GPC $[13,26]$ incluyeron recomendaciones sobre el tratamiento de las AMOM- ERC en pacientes con trasplante renal. Una RS [47] reporta sobre intervenciones para prevenir la enfermedad ósea en pacientes con trasplante renal.

La paratiroidectomía es recomendada cuando hay hipercalcemia persistente después del trasplante. En pacientes con trasplante que tienen función renal estable y no en diálisis no se recomienda la paratiroidectomía o el trasplante autólogo de paratiroides [13]. No se recomienda el trasplante renal en casos de hiperparatiroidismo severo hasta que sean tratados de manera adecuada médica o quirúrgicamente [13].

La RS de Palmer et al. [47] evaluó los beneficios y los riesgos del uso de bifosfonatos, calcimiméticos, vitamina D, teriparatida, denosumab, cinacalcet, paratiroidectomía y calcitonina después del trasplante renal. Se evaluaron como desenlaces primarios las fracturas óseas y el rechazo agudo del injerto; como desenlaces secundarios evaluaron la mortalidad por todas las causas y cardiovascular, infarto del miocardio, accidente cerebrovascular, deformidades óseas, dolor óseo, pérdida del injerto, náuseas, hiper o hipocalcemia, función renal, PTH y DMO. El uso de bifosfonatos durante 12 meses, comparado con placebo, disminuyó el riesgo de fracturas (RR: 0,62 IC $95 \%$ 0,38 - 1,01), rechazo agudo del injerto (RR: 0,70 IC $95 \%$ 0,55 0,89) y dolor óseo (RR: 0,20 IC $95 \%$ 0,04 - 0,93), pero con certeza baja o muy baja; aumentó el riesgo de hipocalcemia (RR: 5,59 IC $95 \%$ 1,00 - 31,06). El efecto de componentes de la vitamina $\mathrm{D}$, análogos no selectivos y selectivos de vitamina D, sobre fracturas, muertes, eventos cardiovasculares y función del injerto en comparación con placebo fue de incertidumbre ante la certeza baja o muy baja de la evidencia.

Una incertidumbre similar fue hallada para otras intervenciones comparadas con placebo.

El estudio observacional del 2018 de Araujo et al. se realizó con el fin de evaluar el impacto del hiperparatiroidismo secundario un año después del trasplante renal. El análisis incluyó 
a 911 pacientes con trasplante renal y tasa de filtración glomerular $>30 \mathrm{ml} / \mathrm{min}$ al año del procedimiento. Durante este periodo se encontró que el $62 \%$ de los pacientes presentó hiperparatiroidismo persistente con niveles altos de calcio, fósforo, PTH y FA. Después de un promedio de seguimiento de 47 meses, el 6,5\% de los pacientes tuvo fracaso del injerto (regreso a diálisis); de estos, el $83 \%$ ocurrió en el grupo de pacientes con hiperparatiroidismo persistente [48].

\section{Recomendaciones}

- Se sugiere la paratiroidectomía en pacientes trasplantados con hipercalcemia persistente, aunque debe ser la última alternativa de elección.

\section{Fuerte a favor}

- Se sugiere manejo médico conservador de la hipercalcemia con calcimiméticos.

\section{Opinión de expertos}

\section{Diagnóstico y tratamiento de la osteoporosis en ERC}

\section{5. ¿Cuál es la indicación de la densitometría ósea según el estadio de la ERC?}

Tres GPC $[13,14,17]$ incluyeron recomendaciones sobre el uso de la densitometría ósea en pacientes con ERC. Chen y Bushinsky [14] recomendaron su uso en pacientes en estadios del G3a al G5D con evidencia de AMOM-ERC con o sin factores de riesgo de osteoporosis, con la finalidad de evaluar el riesgo de fractura si los resultados pueden impactar en las decisiones de tratamiento. La GPC realizada en Ecuador en el 2018 [17] recomendó el uso de pruebas para determinación de DMO de manera rutinaria, ya que permite predecir el riesgo de fractura, aunque no permite detectar el tipo de osteodistrofia renal. Liu et al. [13] sugieren medir regularmente la densitometría ósea de columna lumbar y de cadera en pacientes con ERC en estadios G1 y G2 con osteoporosis.

\section{Recomendaciones}

- Realizar densitometría ósea a pacientes con ERC en estadios de G3a a G5D con evidencia de AMOM-ERC con o sin factores de riesgo de osteoporosis.

\section{Débil a favor}

\section{6. ¿Cuál es el tratamiento farmacológico recomendado para pacientes con osteopo- rosis y ERC?}


Cuatro GPC [13-15,17] generaron recomendaciones sobre el tratamiento farmacológico de los pacientes con osteoporosis y ERC. Los bifosfonatos han sido recomendados para la prevención y el tratamiento de la osteoporosis en pacientes con TFG $\geq 30 \mathrm{~mL} / \mathrm{min} / 1,73$ $\mathrm{m}^{2}$ (estadios G1, G2 y G3) 13 . Otras guías recomiendan usar bifosfonatos, al igual que en la población general, en pacientes con ERC en estadios del G1 al G2 con osteoporosis e independientemente del riesgo de fractura [13]; también para pacientes en estadios del G3 al G4 con anormalidades bioquímicas relacionadas con AMOM-ERC y baja DMO o fracturas por fragilidad. En pacientes en estadio G5 de la ERC se sugirió descartar enfermedad ósea adinámica basada en anormalidades Se recomienda la vitamina $D$ activa o sus análogos y calcio en pacientes en estadios de G3b a G5 bioquímicas o biopsia de hueso antes de prescribir un bifosfonato $[15,17]$.

Chen y Bushinsky [14] sugieren que para los pacientes con ERC de G3a a G3b con PTH normal y osteoporosis o riesgo de fracturas, ser manejados como la población general; por otro lado, sugieren en los pacientes con ERC de G3a a G5D con anormalidades bioquímicas relacionadas con AMOM-ERC y baja DMO o fracturas por fragilidad, un tratamiento de elección que debe tener en cuenta la magnitud y la reversibilidad de las alteraciones bioquímicas y la progresión de la ERC, considerando una biopsia de hueso.

De manera complementaria, se ha sugerido el uso de los bifosfonatos basado en sus características, el tipo de recambio óseo, la función renal y las reacciones adversas de cada medicamento [13].

La prescripción de vitamina D activa o sus análogos y calcio se han propuesto en pacientes con ERC en estadios de G1 a G2 con osteoporosis o alto riesgo de fracturas, al igual que los pacientes en estadios de G3a a G3b que tengan los niveles de PTH dentro de los niveles normales. También se recomienda la vitamina $\mathrm{D}$ activa o sus análogos y calcio en pacientes en estadios de G3b a G5 con anormalidades bioquímicas de AMOM-ERC, baja densidad ósea o fracturas de fragilidad, en quienes se sugiere tener en cuenta la magnitud y la reversibilidad de las anormalidades bioquímicas y la progresión de la enfermedad renal bajo la consideración de una biopsia de hueso [13].

Con relación a la terapia con calcitonina en pacientes con ERC se ha indicado su uso en pacientes con osteoporosis cuando otros tratamientos farmacológicos hayan sido inefectivos incluyendo osteoporosis con alto remodelado óseo, osteoporosis senil y osteoporosis inducida 
por glucocorticoides, para lo cual se recomendó la suplementación con calcio y vitamina $\mathrm{D}$ de acuerdo con las necesidades individuales para prevenir la progresión de la pérdida de masa esquelética. También se sugirió en dolor óseo causado por la osteólisis u osteopenia y pacientes con ERC con hipercalcemia severa [13].

En mujeres con osteoporosis posmenopáusica y hombres con osteoporosis primaria, o con osteoporosis secundaria a deterioro sexual u osteoporosis inducida por glucocorticoides con alto riesgo de fractura, para quienes los agentes antirresortivos han demostrado ser ineficaces, la PTH recombinante puede aumentar la densidad ósea y mejorar la remodelación ósea [13].

En pacientes con enfermedad crónica en estadios de G1 a G2 con osteoporosis inducida por deficiencia de estrógeno, como las mujeres en periodo de menopausia menores de 60 años o las mujeres posmenopáusicas, especialmente con síntomas menopáusicos y atrofia genitourinaria, los agentes estrogénicos podrían usarse para el tratamiento de la osteoporosis. Finalmente, en pacientes con enfermedad crónica en estadios de G1 a G2 con osteoporosis grave o fracturas y a las mujeres a las que se les diagnostica definitivamente osteoporosis posmenopáusica pueden tratarse con moduladores del receptor de estrógenos, y para las mujeres posmenopáusicas con ERC en estadios de G3b a G5 se puede considerar el uso de moduladores del receptor de estrógeno cuando la PTH está bien controlada [13].

\section{Recomendaciones}

- Se sugiere el uso de bifosfonatos en pacientes con ERC en estadios del G1 al G3 (TFG $\geq 30 \mathrm{~mL} / \mathrm{min} / 1,73 \mathrm{~m}^{2}$ ), así como en pacientes en estadios del G3 al G4 con anormalidades bioquímicas relacionadas con AMOM-ERC y baja DMO con o sin fracturas.

\section{Fuerte a favor}

- No se recomienda el uso de bifosfonatos en pacientes con ERC en estadio G5 con enfermedad ósea adinámica.

\section{Fuerte en contra}

- Considerar el estadio de la ERC para la elección del bifosfonato.

\section{Opinión de expertos}

- Se sugiere el uso de vitamina D activa o de sus análogos para pacientes con ERC en estadios G1 y G2 y osteoporosis, así como en pacientes en estadios del G3a al G3b con niveles de PTH normales, osteoporosis con o sin alto riesgo de fractura.

\section{Fuerte a favor}


- Considerar la magnitud y la reversibilidad de las anormalidades bioquímicas y la progresión de la enfermedad renal durante la prescripción de vitamina $\mathrm{D}$ en pacientes en estadios del G3b al G5 con anormalidades bioquímicas de AMOM-ERC, baja densidad ósea y fracturas por fragilidad.

\section{Fuerte a favor}

- Se sugiere el uso de PTH recombinante en mujeres con osteoporosis posmenopáusica y hombres con osteoporosis masculina primaria, con osteoporosis secundaria a deterioro sexual u osteoporosis inducida por glucocorticoides.

\section{Débil a favor}

\section{7. ¿Cómo se realiza el diagnóstico de osteoporosis en pacientes con trasplante renal?}

Tres GPC [13, 14, 26] incluyen recomendaciones sobre el diagnóstico de osteoporosis en pacientes con trasplante renal. Las dos primeras recomiendan la medición de DMO en pacientes con ERC en estadios del G1T al G5T con riesgo de osteoporosis, para identificar el riesgo de fractura, y la última no recomienda la medición de la densidad ósea mineral como parte de la evaluación para el trasplante.

\section{Recomendaciones}

- Se sugiere la medición de la densidad ósea mineral en pacientes trasplantados con riesgo de osteoporosis.

Fuerte a favor

\section{¿Cuál es el manejo recomendado para pacientes con osteoporosis y trasplante renal?}

Tres GPC [13,14,47] emitieron recomendaciones sobre el manejo de los pacientes con osteoporosis y trasplante renal, la primera de ellas recomienda que las intervenciones luego del trasplante incluyan la prevención de la pérdida de hueso y fractura mediante el uso de vitamina D, bifosfonatos, denosumab y calcitonina, de acuerdo con el riesgo individual [47]. Para pacientes con TFG $>30 \mathrm{~mL} / \mathrm{min} \times 1,73 \mathrm{~m}^{2}$ y baja DMO dentro de los 12 meses luego del trasplante, las GPC recomiendan el tratamiento con vitamina D activa y sus análogos o bifosfonatos $[13,14]$.

Adicionalmente, se debe considerar lo siguiente: 
1. La presencia o ausencia de AMOM-ERC debe ser tomado en cuenta durante la selección del agente terapéutico de acuerdo con la evaluación de calcio, fósforo, PTH, ALP y 25(OH)vitamina D [13,14].

2. La biopsia de hueso se puede tomar en cuenta para guiar el tratamiento.

3. En pacientes en estadios de G4T a G5T, en quienes sea conocida la baja DMO, se sugiere manejar igual que los pacientes en estadios de G4 a G5 que no están en diálisis.

4. No hay evidencia actual que guíe el tratamiento de los pacientes más allá de los 12 meses del trasplante $[13,14]$.

La cohorte descrita en el 2019 por Nanmoku et al. [49] tuvo como objetivo esclarecer el efecto del denosumab sobre la hipercalcemia complicada con pérdida de la DMO en pacientes con trasplante renal. Se estudiaron 100 pacientes que fueron clasificados en dos grupos: hipercalcemia severa $(\mathrm{n}=16)($ Ca sérico $>11 \mathrm{mg} / \mathrm{dl})$ y grupo control $(\mathrm{n}=84)($ Ca sérico < $11 \mathrm{mg} / \mathrm{dl})$.

El denosumab $(60 \mathrm{mg})$ fue aplicado a 14 de los 16 integrantes del grupo de hipercalcemia severa (se excluyeron dos por indicación de paratiroidectomía) cada seis meses, sin administración de bifosfonato, vitamina $\mathrm{D}$ activa o calcimiméticos. La terminación del tratamiento se justificó ante la normalización de la DMO.

En los pacientes del grupo de hipercalcemia predominaron las mujeres, más tiempo previo en diálisis y un nivel de PTH basal más alto; de ellos, al inicio del estudio siete presentaron

las GPC recomiendan el tratamiento con vitamina $D$ activa y sus análogos o bifosfonatos osteopenia y siete osteoporosis. Hubo una disminución de los niveles de calcio en suero y FA, aunque no hubo diferencias en concentraciones de PTH. Respecto a la DMO se reportó un incremento en la columna lumbar de 0,89 (DE: 0,22) $\mathrm{g} / \mathrm{cm}^{2}$ a 0,93 (DE: 0,21) g/ $\mathrm{cm}^{2} 12$ meses posteriores a la primera aplicación del denosumab. Nanmoku et al. [49] concluyen que el denosumab debería ser considerado en pacientes con trasplante renal que presenten hipercalcemia severa y pérdida de la DMO.

\section{Recomendaciones}

- Se sugiere que el tratamiento de pacientes trasplantados y con osteoporosis sea individualizado, considerando la presencia de AMOM-ERC y el tipo de medicamentos 
disponibles.

Fuerte a favor

- Considerar entre las alternativas de tratamiento del paciente con trasplante renal y osteoporosis la vitamina $\mathrm{D}$, bifosfonatos, denosumab y calcitonina de acuerdo con el riesgo individual.

Débil a favor

\section{Conflicto de intereses}

Los expertos declararon conflicto de intereses, tal como se reporta en la tabla 2. Los demás autores declaran no tener conflicto de intereses.

\section{Responsabilidades éticas}

\section{Protección de personas y animales}

Los autores declaran que para esta investigación no se han realizado experimentos en seres humanos ni en animales.

\section{Confidencialidad de los datos}

Los autores declaran que han seguido los protocolos de su centro de trabajo sobre la publicación de datos de pacientes.

\section{Derecho a la privacidad y consentimiento informado}

Los autores declaran que en este artículo no aparecen datos de pacientes.

\section{Contribución de los autores}

Jorge Coronado, Erika Yama, Andrés Hernández, Juan Guevara, Elizabeth Alzate, Mercedes Alfaro, José Arango, Astrid Hernández, Cesar Restrepo y Gustavo Aroca participaron en el diseño y ejecución del consenso. Los demás autores participaron como expertos clínicos en la consulta de recomendaciones. Todos los autores participaron en la construcción del manuscrito y aprobaron su contenido. 
Tabla 2. Conflicto de intereses declarado por los miembros del grupo de consenso

\begin{tabular}{|c|c|}
\hline Participante & Declaración (extracción idéntica del formato) \\
\hline Jorge Rico & Conferencista en varias compañías farmacéuticas \\
\hline Fernando Manzur Jattin & Abbott noviembre 2020. MSD 2018 INPROVE II \\
\hline Omar de Jesús Cabarcas Barbosa & Speaker Alexión \\
\hline Fernán del Cristo Mendoza Beltrán & Conferencista Pfizer-Novartis \\
\hline Kateir Contreras & Conferencista en eventos manos aliadas, evaluación de función renal \\
\hline Angelica Roncallo & Actividades educativas, congresos febrero 2020, Laboratorio Boydorr \\
\hline Orlando Olivares & Conferencista \\
\hline José Gabriel López Garcés & Actividad educativa patrocinada por Sanofi, Fresenius 2020 \\
\hline Elkin Machacón Miranda & Speaker Hipertensión Sanofi 2019 \\
\hline Rita Magola Sierra Merlano & $\begin{array}{l}\text { ADVISOR BOARD EPI. Boehringer-Ingelheim. Sep. 2020.PH } \\
\text { Hypertension and Rheumatology-Virtual }\end{array}$ \\
\hline Carolina Larrarte Arenas & $\begin{array}{l}\text { 54th ERA-EDTA Congress, European Renal Association, } \\
\text { European Dialysis and Transplant Association. } \\
\text { Madrid, españa, } 3 \text { a } 6 \text { de junio del } 2017 \text { (roche) } \\
\text { Renal Pathology course. ISN World Congress of } \\
\text { Neprhology. International Society of Nephrology. Ciudad de México, } \\
21 \text { a } 25 \text { de abril de } 2017 . \\
\text { (Alexión) Latin American Speaker Training Meeting. Alexión } \\
\text { Pharmaceuticals. Buenos Aires, } 5 \text { a } 6 \text { de mayo del 2016. (alexion) } \\
\text { Directora médica de RCS Hospital Militar Central }\end{array}$ \\
\hline Roberto Ramírez Marmolejo & Abvie, Boheringer \\
\hline Juan Sebastián Gélvez Rueda & Investigador estudio ASCEND-ND \\
\hline Adolfo Rafael Pertuz Pinzon & FRESENIUS KABI \\
\hline Alejandro Roman & Sanofi, Novartis, Novo Nordisk, Amgen. PTC. Año 2020. \\
\hline Luis Ramón Barros Camargo & Conferencias laboratorios \\
\hline Iván Villegas & Congreso AstraZeneca 2021 \\
\hline Érica Yama & $\begin{array}{l}\text { Speaker Abbvie - Hiperparatirodismo secundario } \\
\text { Speaker Novonordisk - Diabetes Mellitus tipo } 2\end{array}$ \\
\hline
\end{tabular}

Fuente: elaboración propia.

\section{Referencias}

[1] Schoolwerth AC, Engelgau MM, Hostetter TH. A public health action plan is needed for chronic kidney disease. Adv Chronic Kidney Dis. 2005;12(4):418-23. $\uparrow$ Ver página 4

[2] Hill NR, Fatoba ST, Oke JL, Hirst JA, O’Callaghan CA, Lasserson DS, et al. Global prevalence of chronic kidney disease - A systematic review and meta-analysis. PLoS One. 
2016;11(7):e0158765. 个Ver página 4

[3] Ministerio de Salud y Protección Social; Ministerio de Hacienda y Crédito Público. Cuenta de Alto Costo [Internet]. 2020 my. 30 [citado 2021 febr. 11]. Disponible en: https:/ cuentadealtocosto.org/site/quienes-somos/ $\uparrow$ Ver página 4

[4] Cuenta de Alto Costo Colombia. Situación de la Enfermedad Renal Crónica, la Hipertensión Arterial y la Diabetes Mellitus en Colombia, 2019. Cuenta Alto Costo [Internet]. 2019 [citado 2021 Feb 11];1(23226323):293. Disponible en: https:/cuentadealtocosto.org/site/download/ situacion-de-la-enfermedad-renal-cronica-la-hipertension-arterial-y-diabetes-mellitus-en\ -colombia-2019/ $\uparrow$ Ver páginas 4, 5, 6

[5] Zoccali C, Vanholder R, Massy ZA, Ortiz A, Sarafidis P, Dekker FW, et al. The systemic nature of CKD. Nat Rev Nephrol. 2017;13(6):344-58. $\uparrow$ Ver páginas 4, 12

[6] Moe S, Drüeke T, Cunningham J, Goodman W, Martin K, Olgaard K, et al. Definition, evaluation, and classification of renal osteodystrophy: a position statement from Kidney Disease: Improving Global Outcomes (KDIGO). Kidney Int. 2006;69(11):1945-53. 个Ver página 5

[7] Liabeuf S, McCullough K, Young EW, Pisoni R, Zee J, Reichel H, et al. International variation in the management of mineral bone disorder in patients with chronic kidney disease: Results from CKDopps. Bone. 2019;129:115058. $\uparrow$ Ver página 5

[8] Luján MA, Ramírez JA, Acevedo JM, Gómez S, Cañas JM, Santander D, et al. Prevalencia de las alteraciones del metabolismo óseo-mineral asociadas a enfermedad renal crónica no en diálisis. Rev Colomb Nefrol [Internet]. 2019 mzo 1;6(Artículo de investigación original):1725. Disponible en: https://revistanefrologia.org/index.php/rcn/article/view/311 $\uparrow$ Ver página 5

[9] Nakai S, Watanabe Y, Masakane I, Wada A, Shoji T, Hasegawa T, et al. Overview of regular dialysis treatment in Japan (as of 31 December 2011). Ther Apher Dial. 2013;17(6):567-611. 个Ver página 6

[10] Colombia Compra Eficiente [sitio virtual]. Tratamiento de enfermedad renal crónica. Bogotá: Colombia Compra Eficiente; 2020 [citado 2021 febr. 11]. Disponible en: https:/www.colombiacompra.gov.co/tienda-virtual-del-estado-colombiano/salud/ tratamiento-de-enfermedad-renal-cronica $\uparrow$ Ver página 6

[11] The Economist. Value-based health in renal care in Latin America. London: The Economist; 2017. Disponible en: http:/www.eiu. com/graphics/assets/images/public/VBH-in-Renal-Care-in-Latin-America/ Value-based-health-in-renal-care-in-Latin-America.pdf $\uparrow$ Ver página 6 
[12] Belozeroff V, Chertow GM, Graham CN, Dehmel B, Parfrey PS, Briggs AH. Economic evaluation of cinacalcet in the United States: The EVOLVE Trial. Value Health. 2015;18(8):107987. $\uparrow$ Ver página 6

[13] Liu ZH, Li G, Zhang L, Chen J, Chen X, Zhao J, et al. Executive summary: Clinical practice guideline of chronic kidney disease - mineral and bone disorder (CKD-MBD) in China. Kidney Dis (Basel). 2019;5(4):197-203. 个Ver páginas 11, 12, 14, 15, 17, 18, 19, 20, 24, 25, 26, $27,31,32,33,34,35,36,37$

[14] Kidney Disease: Improving Global Outcomes (KDIGO) CKD-MBD Update Work Group. KDIGO 2017 Clinical Practice Guideline Update for the Diagnosis, Evaluation, Prevention, and Treatment of Chronic Kidney Disease-Mineral and Bone Disorder (CKD-MBD). Kidney Int Suppl. 2017;7:1-59. 个Ver páginas 11, 12, 14, 15, 17, 18, 19, 20, 24, 25, 31, 33, 34, 36, 37

[15] Forbes A, Gallagher H. Chronic kidney disease in adults: Assessment and management. Clinical medicine (Londres, Inglaterra). 2020;20(2):128-32. $\uparrow$ Ver páginas 19, 24, 25, 26, 34

[16] Malaysian Health Technology Assessment Section. Management of Chronic Kidney Technology Disease. Putrajaya, Assessment Section; Malasia: 2018. Malaysian Disponible Health en: https:/www.moh.gov.my/moh/resources/penerbitan/CPG/CPG\% 20Management\%20of\%20Chronic\%20Kidney\%20\%20Disease\%20(Second\%20Edition).pdf

个Ver páginas 12, 20, 27

[17] Ministerio de Salud Pública del Ecuador. Prevención, diagnóstico y tratamiento de la enfermedad renal crónica. Guía de práctica clínica. Quito: Ministerio de Salud Pública, Dirección Nacional de Normatización- MSP; 2018. Disponible en: https:/www.salud.gob.ec/wp-content/uploads/2018/10/ guia_prevencion_diagnostico_tratamiento_enfermedad_renal_cronica_2018.pdf $\uparrow$ Ver páginas $11,12,14,15,18,19,20,24,27,31,33,34$

[18] De Maré A, Verhulst A, Cavalier E, Delanaye P, Behets GJ, Meijers B, et al. Clinical inference of serum and bone sclerostin levels in patients with end-stage kidney disease. J Clin Med. 2019;8(12):2027. 个Ver página 14

[19] Druck A, Patel D, Bansal V, Hoppensteadt D, Fareed J. Osteopontin levels in patients with chronic kidney disease stage 5 on hemodialysis directly correlate with intact parathyroid hormone and alkaline phosphatase. Clin Appl Thromb. 2019;25:1-5. 个Ver página 14

[20] Sprague SM, Bellorin-Font E, Jorgetti V, Carvalho AB, Malluche HH, Ferreira A, et al. Diagnostic accuracy of bone turnover markers and bone histology in patients with CKD treated by dialysis. Am J Kidney Dis. 2016;67(4):559-66. $\uparrow$ Ver página 14 
[21] Aaltonen L, Koivuviita N, Seppänen M, Tong X, Kröger H, Löyttyniemi E, et al. Correlation between 18F-Sodium Fluoride positron emission tomography and bone histomorphometry in dialysis patients. Bone. 2020;134:115267. $\uparrow$ Ver página 15

[22] Baptista AL, Padilha K, Malagrino PA, Venturini G, Zeri AC, Dos Reis LM, et al. Potential biomarkers of the turnover, mineralization, and volume classification: Results using NMR metabolomics in hemodialysis patients. JBMR plus. 2020;4(7):e10372-e. $\uparrow$ Ver página 15

[23] Aigner C, Cejka D, Sliber C, Fraunschiel M, Sunder-Plassmann G, Gaggl M. Oral sodium bicarbonate supplementation does not affect serum calcification propensity in patients with chronic kidney disease and chronic metabolic acidosis. Kidney Blood Press Res.

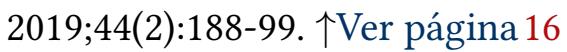

[24] Chen Z, Qureshi AR, Ripsweden J, Wennberg L, Heimburger O, Lindholm B, et al. Vertebral bone density associates with coronary artery calcification and is an independent predictor of poor outcome in end-stage renal disease patients. Bone. 2016;92:50-7. $\uparrow$ Ver página 16

[25] Chen Z, Sun J, Haarhaus M, Barany P, Wennberg L, Ripsweden J, et al. Bone mineral density of extremities is associated with coronary and biopsy-verified vascular calcification in living-donor renal transplant recipients. J Bone Miner Metab. 2017;35(5):536-43. 个Ver página 16

[26] Chadban SJ, Ahn C, Axelrod DA, Foster BJ, Kasiske BL, Kher V, et al. KDIGO Clinical Practice Guideline on the Evaluation and Management of Candidates for Kidney Transplantation. Transplantation. 2020;104(4S1 Supl. 1):s11-s103. 个Ver páginas 17, 32, 36

[27] Ikizler TA, Burrowes JD, Byham-Gray LD, Campbell KL, Carrero JJ, Chan W, et al. KDOQI clinical practice guideline for nutrition in CKD: 2020 update. Am J Kidney Dis. 2020;76(3 Supl. 1):s1-s107. $\uparrow$ Ver páginas 18, 19

[28] Yadav AK, Kumar V, Kumar V, Banerjee D, Gupta KL, Jha V. The effect of vitamin D supplementation on bone metabolic markers in chronic kidney disease. J Bone Miner Res. 2018;33(3):404-9. $\uparrow$ Ver página 20

[29] Ruospo M, Palmer SC, Natale P, Craig JC, Vecchio M, Elder GJ, et al. Phosphate binders for preventing and treating chronic kidney disease- mineral and bone disorder (CKD-MBD). The Cochrane database of systematic reviews. 2018;8(8):CD006023-CD. $\uparrow$ Ver páginas 20, 21, 22

[30] Sekercioglu N, Thabane L, Díaz-Martínez JP, Nesrallah G, Longo CJ, Busse JW, et al. Comparative effectiveness of phosphate binders in patients with chronic kidney disease: A sys- 
tematic review and network meta-analysis. PLoS One. 2016;11(6):e0156891. $\uparrow$ Ver páginas 20,21

[31] Sekercioglu N, Angeliki-Veroniki A, Thabane L, Busse JW, Akhtar- Danesh N, Iorio A, et al. Effects of different phosphate lowering strategies in patients with CKD on laboratory outcomes: A systematic review and NMA. PLoS One. 2017;12(3):e0171028. $\uparrow$ Ver páginas 20, 21

[32] De Roij-Van Zuijdewijn CL, De Haseth DE, Van Dam B, Bax WA, Grooteman MPC, Bots ML, et al. Role of albumin assay on calcium levels and prescription of phosphate binders in chronic hemodialysis patients. Nephron. 2018;140(3):211-7. 个Ver página 22

[33] Block GA, Rosenbaum DP, Leonsson-Zachrisson M, Åstrand M, Johansson S, Knutsson M, et al. Effect of tenapanor on serum phosphate in patients receiving hemodialysis. J Am

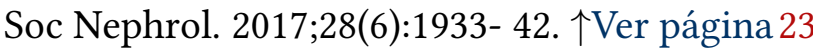

[34] Block GA, Rosenbaum DP, Yan A, Chertow GM. Efficacy and safety of tenapanor in patients with hyperphosphatemia receiving maintenance hemodialysis: A randomized phase 3 Trial. J Am Soc Nephrol. 2019;30(4):641-52. 个Ver página 23

[35] Malhotra R, Katz R, Hoofnagle A, Bostom A, Rifkin DE, McBride R, et al. The effect of extended release niacin on markers of mineral metabolism in CKD. Clin J Am Soc Nephrol. 2018;13(1):36-44. $\uparrow$ Ver página 24

[36] Sekercioglu N, Busse JW, Sekercioglu MF, Agarwal A, Shaikh S, Lopes LC, et al. Cinacalcet versus standard treatment for chronic kidney disease: a systematic review and metaanalysis. Ren Fail. 2016;38(6):857-74. $\uparrow$ Ver páginas 25, 26

[37] Ni LH, Yuan C, Song KY, Wang XC, Chen SJ, Wang LT, et al. Efficacy and safety of cinacalcet and active vitamin $\mathrm{D}$ in the treatment of secondary hyperparathyroidism in patients with chronic kidney disease: A network meta-analysis. Ann Transl Med. 2019;7(14):322. $\uparrow$ Ver página 25

[38] Greeviroj P, Kitrungphaiboon T, Katavetin P, Praditpornsilpa K, Eiam-Ong S, Jaber BL, et al. Cinacalcet for treatment of chronic kidney disease- mineral and bone disorder: A metaanalysis of randomized controlled trials. Nephron. 2018;139(3):197-210. 个Ver páginas 25, 26, 27

[39] Palmer SC, Mavridis D, Johnson DW, Tonelli M, Ruospo M, Strippoli GFM. Comparative effectiveness of calcimimetic agents for secondary hyperparathyroidism in adults: A systematic review and network meta- analysis. Am J Kidney Dis. 2020;76(3):321-30. $\uparrow$ Ver páginas 25,27 
[40] Floege J, Kubo Y, Floege A, Chertow GM, Parfrey PS. The effect of cinacalcet on calcific uremic arteriolopathy events in patients receiving hemodialysis: The EVOLVE Trial. Clin J Am Soc Nephrol. 2015;10(5):800-7. 个Ver página 28

[41] Cozzolino M, Mangano M, Galassi A, Ciceri P, Messa P, Nigwekar S. Vitamin K in chronic kidney disease. Nutrients. 2019;11(1):168. 个Ver página 28

[42] Udomkarnjananun S, Kongnatthasate K, Praditpornsilpa K, Eiam-Ong S, Jaber BL, Susantitaphong P. Treatment of calciphylaxis in CKD: A systematic review and meta-analysis. Kidney international reports. 2018;4(2):231-44. $\uparrow$ Ver página 29

[43] Peng T, Zhuo L, Wang Y, Jun M, Li G, Wang L, et al. Systematic review of sodium thiosulfate in treating calciphylaxis in chronic kidney disease patients. Nephrology. 2018;23(7):66975. $\uparrow$ Ver página 30

[44] Coyne DW, Singh HN, Smith WT, Giuseppi AC, Connarn JN, Sherman ML, et al. Sotatercept safety and effects on hemoglobin, bone, and vascular calcification. Kidney Int Reports. 2019;4(11):1585-97. Ver página 30

[45] Brandenburg VM, Sinha S, Torregrosa JV, Garg R, Miller S, Canals AZ, et al. Improvement in wound healing, pain, and quality of life after 12 weeks of SNF472 treatment: a phase 2 open-label study of patients with calciphylaxis. J Nephrol. 2019;32(5):811-21. 个Ver página 30

[46] Ape trii M, Goldsmith D, Nistor I, Siriopol D, Voroneanu L, Scripcariu D, et al. Impact of surgical parathyroidectomy on chronic kidney disease- mineral and bone disorder (CKDMBD) - A systematic review and meta- analysis. PLoS One. 2017;12(11):e0187025. Ver página 31

[47] Palmer SC, Chung EY, McGregor DO, Bachmann F, Strippoli GF. Interventions for preventing bone disease in kidney transplant recipients. The cochrane database of systematic reviews. 2019;10(10):CD005015- CD. 个Ver página 32, 36

[48] Araujo M, Ramalho JAM, Elias RM, Jorgetti V, Nahas W, Custodio M, et al. Persistent hyperparathyroidism as a risk factor for long-term graft failure: the need to discuss indication for parathyroidectomy. Surgery. 2018;163(5):1144-50. $\uparrow$ Ver página 33

[49] Nanmoku K, Shinzato T, Kubo T, Shimizu T, Takachi Y. Effects of denosumab on hypercalcemia and bone mineral density loss in kidney transplant recipients. Clin Nephrol. 2019;(0301-0430):1-9. 个Ver página 37 


\section{Anexos}

\section{Anexo A. Preguntas clínicas desarrolladas}

\section{Diagnóstico de las CKD-MBD}

1. ¿Cuándo está indicada la realización de estudios de laboratorios exploratorios de alteraciones bioquímicas de CKD-MBD? (Calcio, fósforo, albúmina sérica, PTHi, FA, hidroxi $(\mathrm{OH}) 25$ vitamina $\mathrm{D})$.

2. ¿Cuáles son los métodos diagnósticos alternativos a la biopsia de hueso, recomendados para la detección de alteraciones óseas en pacientes con CKD-MBD?

3. ¿Cuál es el método diagnóstico recomendado para el diagnóstico de calcificación vascular?

4. ¿Cómo se realiza el diagnóstico de alteraciones del metabolismo óseo en pacientes con trasplante renal?

\section{Tratamiento de las CKD-MBD}

5. ¿Cuándo realizar una intervención nutricional en relación con el aporte de micronutrientes (calcio y fósforo) en pacientes con CKD-MBD?

6. ¿Cuál es la indicación de suplementación con vitamina D en pacientes con CKD-MBD?

7. ¿Cuál quelante intestinal del fósforo utilizar para el manejo de la hiperfosfatemia en CKD-MBD?

8. ¿Cuál es la indicación de los medicamentos bloqueadores de la absorción intestinal de fósforo?

9. ¿Cuál es la indicación de activadores del receptor de vitamina D en el tratamiento de hiperparatiroidismo? (Análogos no selectivos de vitamina D: calcitriol, doxercalciferol, calcidiol, alfacalcidiol. Análogos selectivos: paricalcitol).

10. ¿Cuál es la indicación para el uso de calcimiméticos en CKD-MBD? (Cinacalcet, único disponible en Colombia, vía oral. Además, etelcalcetide de uso intravenoso, no disponible en Colombia).

11. ¿Cuáles son las estrategias de prevención de calcifilaxis recomendadas?

12. ¿Cuál es el tratamiento recomendado para la calcifilaxis? (Quirúrgico: limpieza quirúrgica, paratiroidectomía; médico: larvas estériles, cámara hiperbárica, cinacalcet, tiosulfato de sodio, bifosfonatos, SNF472). 
13. ¿Cuál es la indicación de la paratiroidectomía en el manejo de CKD- MBD?

14. ¿Cuál es el tratamiento recomendado para alteraciones del metabolismo óseo en pacientes con trasplante renal?

\section{Diagnóstico y tratamiento de la osteoporosis en ERC}

15. ¿Cuál es la indicación de osteodensitometría según el estadio de la ERC?

16. ¿Cuál es el tratamiento farmacológico recomendado para pacientes con osteoporosis y ERC?

17. ¿Cómo se realiza el diagnóstico de osteoporosis en pacientes con trasplante renal?

18. ¿Cuál es el manejo recomendado para paciente con osteoporosis y trasplante renal? 


\section{Anexo B. Estrategias de búsqueda}

Tabla 3. Estrategias de búsqueda

\begin{tabular}{|c|c|}
\hline Fuente consultada & Estrategia de búsqueda \\
\hline Pubmed & $\begin{array}{l}\text { ("CKD-MINERAL"[Title/Abstract] AND "bone } \\
\text { disorders"[Title/Abstract]) OR ÇKD-MBD"[Title/Abstract] OR } \\
\text { (çhronic kidney disease mineral"[Title/Abstract] AND "bone } \\
\text { disorder"[Title/Abstract]) OR ((("disordered"[All Fields] OR } \\
\text { "disordering"[All Fields]) AND (çalcification, } \\
\text { physiologic"[MeSH Terms] OR (çalcification"[All Fields] AND } \\
\text { "physiologic"[All Fields]) OR "physiologic calcification"[All } \\
\text { Fields] OR "mineralization"[All Fields] OR "mineral s"[All } \\
\text { Fields] OR "mineralisable"[All Fields] OR "mineralisation"[All } \\
\text { Fields] OR "mineralisations"[All Fields] OR "mineralise"[All } \\
\text { Fields] OR "mineralised"[All Fields] OR "mineralising"[All } \\
\text { Fields] OR "mineralizations"[All Fields] OR "mineralize"[All } \\
\text { Fields] OR "mineralized"[All Fields] OR "mineralizer"[All } \\
\text { Fields] OR "mineralizers"[All Fields] OR "mineralizes"[All Fields] } \\
\text { OR "mineralizing"[All Fields] OR "minerals"[MeSH Terms] OR } \\
\text { "minerals"[All Fields] OR "mineral"[All Fields]) AND } \\
\text { ("metabolic"[All Fields] OR "metabolical"[All Fields] OR } \\
\text { "metabolically"[All Fields] OR "metabolics"[All Fields] OR } \\
\text { "metabolism"[MeSH Terms] OR "metabolism"[All Fields] OR } \\
\text { "metabolisms"[All Fields] OR "metabolism"[MeSH Subheading] } \\
\text { OR "metabolic networks and pathways"[MeSH Terms] OR } \\
\text { ("metabolic"[All Fields] AND "networks"[All Fields] AND } \\
\text { "pathways"[All Fields]) OR "metabolic networks and } \\
\text { pathways"[All Fields] OR "metabolities"[All Fields] OR } \\
\text { "metabolization"[All Fields] OR "metabolize"[All Fields] OR } \\
\text { "metabolized"[All Fields] OR "metabolizer"[All Fields] OR } \\
\text { "metabolizers"[All Fields] OR "metabolizes"[All Fields] OR } \\
\text { "metabolizing"[All Fields])) AND in chronic kidney } \\
\text { disease"[Title/Abstract]) } \\
\text { Filtros aplicados en los últimos cinco años. }\end{array}$ \\
\hline Embase & $\begin{array}{l}\text { \#2 AND (2015:py OR 2016:py OR 2017:py OR 2018:py OR } \\
\text { 2019:py OR 2020:py) } \\
\text { \#1 'chronic kidney disease-mineral and bone disorder'/exp OR } \\
\text { 'ckd-mbd' OR 'ckd-mineral and bone disorder' OR 'chronic } \\
\text { kidney disease-mineral and bone disorder' }\end{array}$ \\
\hline
\end{tabular}

Fuente: elaboración propia. 


\section{Anexo C. Diagrama de flujo - Prisma}

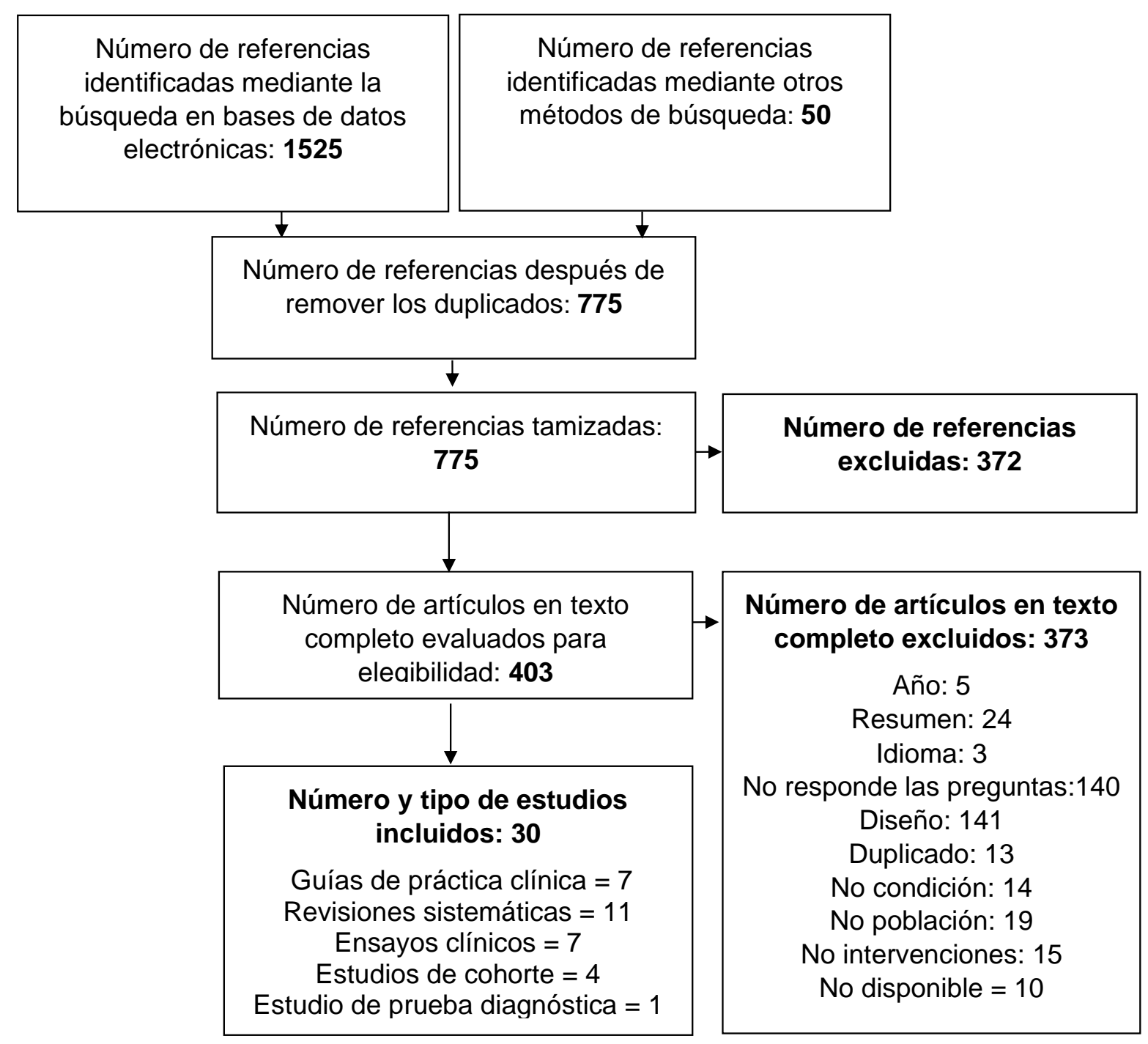

Fuente: elaboración propia 


\section{Anexo D. Evaluación de calidad}

\section{Calificación de GPC}

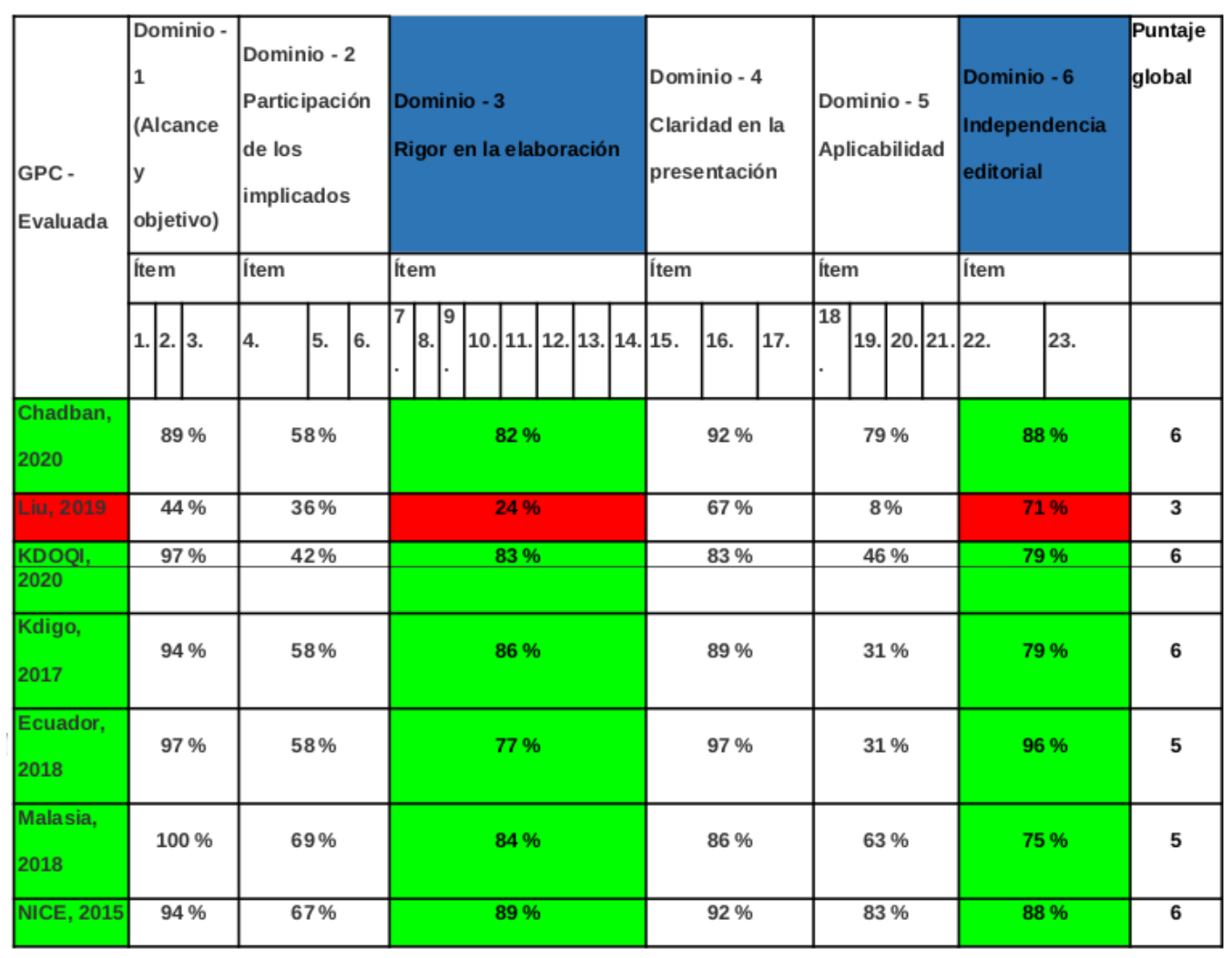

Fuente: elaboración propia. 


\section{Calificación de RSL}

\begin{tabular}{|c|c|c|c|c|c|c|c|c|c|c|c|c|c|c|c|c|c|}
\hline \multirow[b]{2}{*}{ Autor, año } & \multicolumn{17}{|c|}{ Dominios } \\
\hline & 1 & & 3 & & 5 & 6 & & 8 & & 10 & & 12 & & 14 & & 16 & Confianza \\
\hline $\mathrm{Ni}, 2019$ & Sí & No & No & Sí parcial & Sí & Sí & Sí parcial & No & Sí & No & No & No & No & No & Sí & Sí & Críticamente baja \\
\hline Palmer, 2019 & Sí & Sí & Sí & Sí & Sí & Sí & Sí & Sí & Sí & Sí & Sí & Sí & Sí & Sí & Sí & Sí & Alta \\
\hline Ruospo, 2018 & Sí & Sí & Sí & Sí & Sí & Sí & Sí & Sí & Sí & No & Sí & Sí & Sí & Sí & Sí & Sí & Baja \\
\hline Sekercioglu, 2016 & Sí & No & No & Sí parcial & Sí & Sí & No & No & Sí & No & No & $\mathrm{Si}$ & $\mathrm{Si}$ & No & Sí & Sí & Críticamente baja \\
\hline Sekercioglu, 2016 & Sí & Sí & Sí & Sí parcial & Sí & Sí & No & No & Sí & No & No & $\mathrm{Si}$ & $\mathrm{Si}$ & No & Sí & Sí & Críticamente baja \\
\hline Sekercioglu, 2017 & Sí & Sí & Sí & Sí parcial & Sí & Sí & No & No & Sí & No & No & $\mathrm{Si}$ & $\mathrm{Si}$ & No & Sí & Sí & Críticamente baja \\
\hline Greeviroj, 2018 & Sí & No & Sí & Si parcial & Sí & Sí & No & Sí parcial & No & No & No & No & No & Sí & Sí & Sí & Críticamente baja \\
\hline Palmer, 2020 & Sí & Sí & Sí & Si parcial & Sí & Sí & No & No & Sí & No & Sí & No & Sí & No & No & Sí & Críticamente baja \\
\hline Apetrii, 2017 & Sí & Sí parcial & Sí & Si parcial & No & Sí & No & Sí & No & No & No & No & No & No & Sí & Sí & Críticamente baja \\
\hline Peng, 2018 & Sí & No & Sí & No & No & No & No & No & No & No & No ** & N.a. & No & No & No ** & Sí & Críticamente baja \\
\hline Udomkarnjananun, 2018 & Sí & No & Sí & No & No & No & No & No & No & No & No & No & No & No & No & Sí & Críticamente baja \\
\hline
\end{tabular}

Fuente: elaboración propia. 


\section{Calificación de ensayos clínicos}

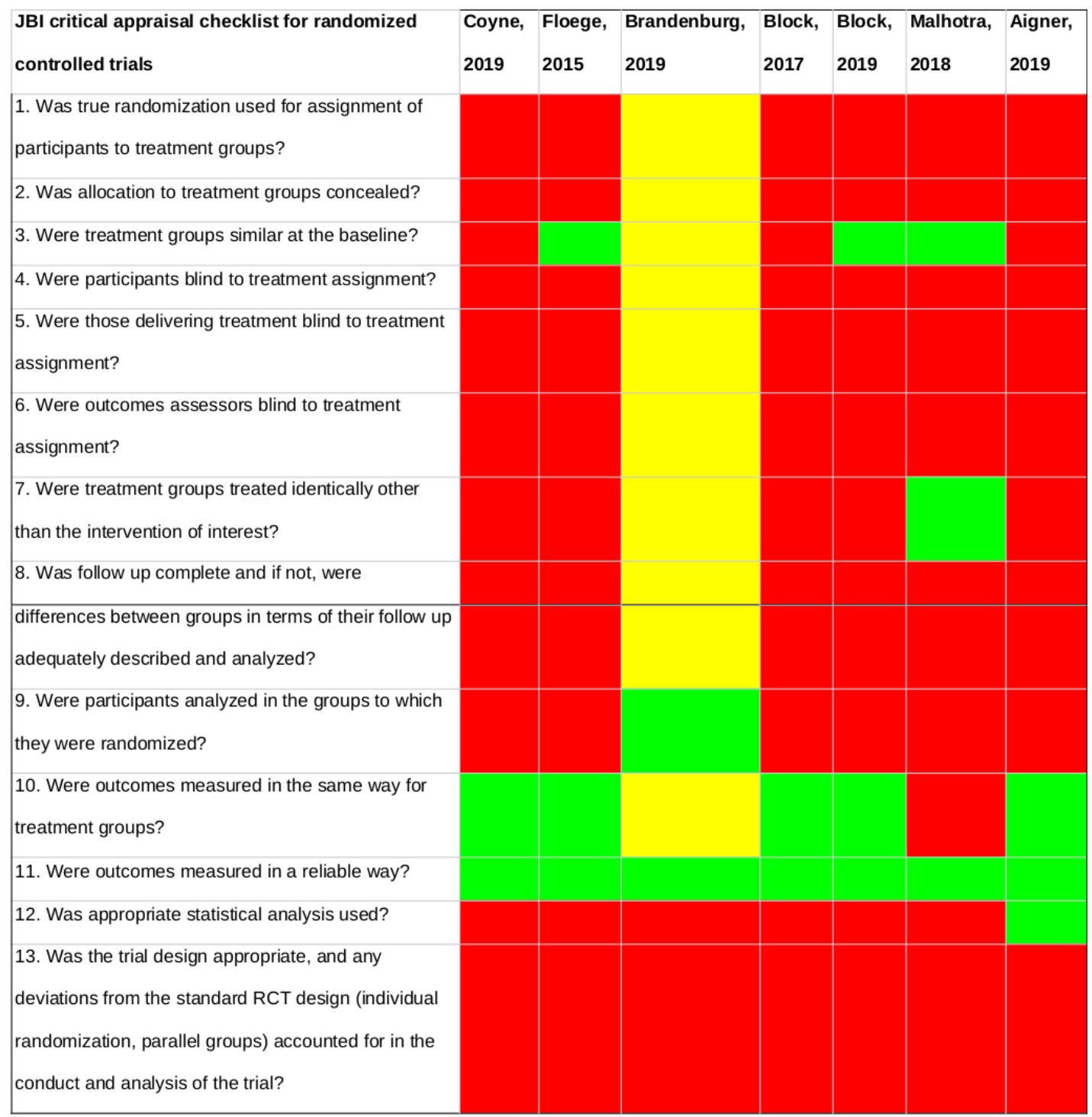

Fuente: elaboración propia. 


\section{Calificación de estudios primarios}

\begin{tabular}{|c|c|c|c|c|}
\hline JBI critical appraisal checklist for cohort studies & $\begin{array}{l}\text { Chen, } \\
2016\end{array}$ & $\begin{array}{l}\text { Chen, } \\
2017\end{array}$ & $\begin{array}{l}\text { Druck, } \\
2019\end{array}$ & $\begin{array}{l}\text { Nanmoku, } \\
2019\end{array}$ \\
\hline $\begin{array}{l}\text { 1. Were the two groups similar and recruited from the same } \\
\text { population? }\end{array}$ & & & & \\
\hline $\begin{array}{l}\text { 2. Were the exposures measured similarly to assign people } \\
\text { to both exposed and unexposed groups? }\end{array}$ & & & & \\
\hline 3. Was the exposure measured in a valid and reliable way? & & & & \\
\hline 4. Were confounding factors identified? & & & & \\
\hline 5. Were strategies to deal with confounding factors stated? & & & & \\
\hline $\begin{array}{l}\text { 6. Were the groups/participants free of the outcome at the } \\
\text { start of the study (or at the moment of exposure)? }\end{array}$ & & & & \\
\hline 7. Were the outcomes measured in a valid and reliable way? & & & & \\
\hline $\begin{array}{l}\text { 8. Was the follow up time reported and sufficient to be long } \\
\text { enough for outcomes to occur? }\end{array}$ & & & & \\
\hline $\begin{array}{l}\text { 9. Was follow up complete, and if not, were the reasons to } \\
\text { loss to follow up described and explored? }\end{array}$ & & & & \\
\hline 10. Were strategies to address incomplete follow up utilized? & & & & \\
\hline 11. Was appropriate statistical analysis used? & & & & \\
\hline
\end{tabular}

Fuente: elaboración propia. 


\section{Calificación de estudios diagnósticos - Sprague 2016}

\begin{tabular}{|c|c|c|c|c|}
\hline $\begin{array}{l}\text { JBI critical appraisal checklist for diagnostic } \\
\text { test accuracy studies }\end{array}$ & Yes 1 & No & Unclear & applicable \\
\hline $\begin{array}{l}\text { 1. Was a consecutive or random sample of } \\
\text { patients enrolled? }\end{array}$ & & & & \\
\hline 2. Was a case control design avoided? & & & & \\
\hline 3. Did the study avoid inappropriate exclusions? & $x$ & & & \\
\hline $\begin{array}{l}\text { 4. Were the index test results interpreted without } \\
\text { knowledge of the results of the reference } \\
\text { standard? }\end{array}$ & & & & \\
\hline 5. If a threshold was used, was it pre-specified? & & & & $\mathrm{x}$ \\
\hline $\begin{array}{l}\text { 6. Is the reference standard likely to correctly } \\
\text { classify the target condition? }\end{array}$ & $\mathrm{x}$ & & & \\
\hline $\begin{array}{l}\text { 7. Were the reference standard results } \\
\text { interpreted without knowledge of the results of } \\
\text { the index test? }\end{array}$ & $\mathrm{x}$ & & & \\
\hline $\begin{array}{l}\text { 8. Was there an appropriate interval between } \\
\text { index test and reference standard? }\end{array}$ & & & & $x$ \\
\hline $\begin{array}{l}\text { 9. Did all patients receive the same reference } \\
\text { standard? }\end{array}$ & $\mathrm{x}$ & & & \\
\hline 10. Were all patients included in the analysis? & & & i & \\
\hline
\end{tabular}

Fuente: elaboración propia. 


\section{Resultados de la votación de la consulta preconsenso}

\begin{tabular}{|c|c|}
\hline Recomendación & \% de acuerdo \\
\hline $\begin{array}{l}\text { Se recomienda: [Realizar estudios de laboratorios } \\
\text { exploratorios de alteraciones bioquímicas de AMOM-ERC, } \\
\text { incluyendo calcio sérico, fosfato sérico, PHT, } 25 \mathrm{OH} \text { vitamina } \\
\text { D, bicarbonato (HCO3-) y FA a partir del estadio G3a de la } \\
\text { ERC.] }\end{array}$ & 100,0 \\
\hline $\begin{array}{l}\text { Se recomienda: [Realizar calcio, fósforo y FA en suero en } \\
\text { función del estadio de la ERC, de manera que para estadios } \\
\text { G3a y G3b se realice de forma semestral o anual; en estadio } \\
\text { G4 se realice cada tres meses y máximo cada seis meses, y } \\
\text { para el estudio G5 se realice mensual o trimestral de acuerdo } \\
\text { con el juicio clínico.] }\end{array}$ & 93,6 \\
\hline $\begin{array}{l}\text { Se recomienda: [Realizar estudio exploratorio de PTH para } \\
\text { estadios G3a y G3b de acuerdo con niveles de referencia y } \\
\text { progresión de la enfermedad. Para el estadio G4 se } \\
\text { recomienda medición semestral o anual y en estadio G5 } \\
\text { medición cada tres meses y máximo cada seis meses.] }\end{array}$ & 93,6 \\
\hline $\begin{array}{l}\text { Se recomienda: [Considerar niveles de referencia del HCO3- } \\
\text { y progresión de la enfermedad en la definición de la } \\
\text { frecuencia de medición de este biomarcador en pacientes } \\
\text { con ERC.] }\end{array}$ & 80,9 \\
\hline $\begin{array}{l}\text { Se sugiere: [Realizar mediciones anuales de calcio, fósforo, } \\
\text { PTH en pacientes con estadios G1 y G2 de la ERC como } \\
\text { estrategia para diagnóstico temprano y prevención de }\end{array}$ & 78,7 \\
\hline
\end{tabular}




\begin{tabular}{|c|c|}
\hline $\begin{array}{l}\text { complicaciones vasculares, considerando las comorbilidades } \\
\text { y el contexto del paciente.] }\end{array}$ & \\
\hline $\begin{array}{l}\text { Se sugiere: [Considerar niveles basales de } 25 \mathrm{OH} \text { vitamina D } \\
\text { e intervenciones para determinar la frecuencia de medición } \\
\text { de este biomarcador en pacientes con ERC.] }\end{array}$ & 93,6 \\
\hline $\begin{array}{l}\text { Se sugiere: [Mediciones de biomarcadores en pacientes en } \\
\text { prediálisis y diálisis con hallazgos de alteraciones, entre uno } \\
\text { y seis meses de acuerdo con la necesidad clínica del } \\
\text { paciente.] }\end{array}$ & 93,6 \\
\hline $\begin{array}{l}\text { Se recomienda: [El uso de biomarcadores (calcio, fósforo, } \\
\text { FA, } 25 \mathrm{OH} \text { vitamina D y PTH) y juicio clínico para el } \\
\text { diagnóstico de AMOM-ERC.] }\end{array}$ & 95,7 \\
\hline $\begin{array}{l}\text { A pesar de la ausencia de biopsia de hueso en Colombia, se } \\
\text { sugiere: [Promover medidas académicas y políticas públicas } \\
\text { para la investigación y desarrollo de esta prueba diagnóstica } \\
\text { por parte de patólogos expertos en el país] }\end{array}$ & 97,9 \\
\hline $\begin{array}{l}\text { Se recomienda: [La realización de radiografía lateral de } \\
\text { abdomen (índice de Kauppila), postero-anterior de manos y } \\
\text { pelvis (índice de Adragao) para la detección de } \\
\text { calcificaciones vasculares.] }\end{array}$ & 91,5 \\
\hline $\begin{array}{l}\text { Se sugiere: [Realizar ecocardiografía en pacientes con ERC } \\
\text { en estadios del G3 al G5 para detectar calcificaciones } \\
\text { valvulares.] }\end{array}$ & 89,4 \\
\hline $\begin{array}{l}\text { Se sugiere: [Realizar tomografía computarizada de tórax de } \\
\text { cortes múltiples para la detección de calcificaciones en las }\end{array}$ & 72,3 \\
\hline
\end{tabular}




\begin{tabular}{|c|c|}
\hline arterias coronarias.] & \\
\hline $\begin{array}{l}\text { En el periodo postrasplante inmediato se recomienda: } \\
\text { [Medición de calcio y fósforo para diagnóstico de AMOM- } \\
\text { ERC.] }\end{array}$ & 87,2 \\
\hline $\begin{array}{l}\text { En el periodo postrasplante inmediato se recomienda: } \\
\text { [Medición semanal de calcio y fósforo en suero hasta niveles } \\
\text { razonables.] }\end{array}$ & 80,9 \\
\hline $\begin{array}{l}\text { Se recomienda: [Medición de calcio y fósforo semestral o } \\
\text { anual, así como medición anual de PTH en estadios del G1 al } \\
\text { Gb3T en fase de postrasplante tardío.] }\end{array}$ & 97,9 \\
\hline $\begin{array}{l}\text { Se recomienda: [Seguimiento de calcio y fósforo mensual o } \\
\text { trimestral en el estadio 5GT y para hormona PTH trimestral o } \\
\text { semestral en paciente trasplantado.] }\end{array}$ & 97,9 \\
\hline $\begin{array}{l}\text { En estadio G4T se recomienda: [Medición bimestral y } \\
\text { máximo semestral de calcio y fósforo en paciente } \\
\text { trasplantado, mientras que para hormona paratiroidea entre } \\
\text { una y dos veces al año.] }\end{array}$ & 97,9 \\
\hline $\begin{array}{l}\text { Se sugiere: [Medición de FA a partir del estadio G3aT al G5T } \\
\text { anualmente o con mayor frecuencia según juicio clínico y } \\
\text { nivel de PTH.] }\end{array}$ & 95,7 \\
\hline $\begin{array}{l}\text { Se recomienda: [Que pacientes con AMOM-ERC reciban } \\
\text { asesoría y seguimiento nutricional.] }\end{array}$ & 100,0 \\
\hline $\begin{array}{l}\text { Se sugiere: [Reducir el consumo de fósforo dietario entre } 800 \\
\text { y } 1.000 \mathrm{mg} / \text { día en pacientes con ERC en estadios del G3a al }\end{array}$ & 95,7 \\
\hline
\end{tabular}




\begin{tabular}{|c|c|}
\hline G5D, a pesar de tener cifras normales de fósforo.] & \\
\hline $\begin{array}{l}\text { Se sugiere: [Restringir el consumo de proteínas y alimentos, } \\
\text { fórmulas, preparados con aditivos que contienen fosfatos } \\
\text { (conservantes, bebidas azucaradas, enlatados, etc.), } \\
\text { considerando cada caso de manera aislada.] }\end{array}$ & 97,9 \\
\hline $\begin{array}{l}\text { Se sugiere: [Suplementación de fosfato en pacientes con } \\
\text { trasplante renal e hipofosfatemia a través de dieta o } \\
\text { suplementos.] }\end{array}$ & 93,6 \\
\hline $\begin{array}{l}\text { Se sugiere: [En los pacientes en diálisis considerar el } \\
\text { contenido de fósforo en medicamentos de consumo crónico } \\
\text { en los pacientes en diálisis, especialmente antihipertensivos } \\
\text { (amlodipino, lisinopril, irbesartan, metoprolol).] }\end{array}$ & 87,2 \\
\hline $\begin{array}{l}\text { Se recomienda: [La prescripción y el uso de colecalciferol o } \\
\text { ergocalciferol para tratar la deficiencia de vitamina D en } \\
\text { pacientes con AMOM-ERC.] }\end{array}$ & 100,0 \\
\hline $\begin{array}{l}\text { Se sugiere: [La prescripción de vitamina D en pacientes con } \\
\text { insuficiencia y niveles de PTH persistentemente elevados.] }\end{array}$ & 95,7 \\
\hline $\begin{array}{l}\text { Se recomienda: [Que la prescripción y el uso de quelantes de } \\
\text { fósforo sea individualizado, considerando características del } \\
\text { paciente, estadio de la enfermedad y tipo de quelante.] }\end{array}$ & 100,0 \\
\hline $\begin{array}{l}\text { Se recomienda: [Evitar el uso de quelantes de fósforo a base } \\
\text { de calcio o de aluminio para pacientes con ERC en estadios } \\
\text { del G3a al G5D.] }\end{array}$ & 59,6 \\
\hline $\begin{array}{l}\text { Se sugiere: [El uso de quelantes de fósforo no cálcico } \\
\text { disponibles en Colombia en casos de hipercalcemia }\end{array}$ & 97,9 \\
\hline
\end{tabular}




\begin{tabular}{|c|c|}
\hline $\begin{array}{l}\text { persistente o recurrente, calcificaciones vasculares y niveles } \\
\text { de PTHi bajos.] }\end{array}$ & \\
\hline $\begin{array}{l}\text { En pacientes en diálisis se sugiere: [El uso de quelante de } \\
\text { fósforo tipo sevelamer y en pacientes en prediálisis el } \\
\text { clorhidrato o carbonato de sevelamer de acuerdo al estado } \\
\text { ácido-base.] }\end{array}$ & 85,1 \\
\hline $\begin{array}{l}\text { Se sugiere: [El uso de bloqueadores de absorción de fósforo } \\
\text { en pacientes con ERC estadio 5, en terapia con hemodiálisis } \\
\text { de mantenimiento y niveles de fosfato sérico de cuatro a siete } \\
\text { mg/dl.] }\end{array}$ & 78,7 \\
\hline $\begin{array}{l}\text { Se recomienda: [La prescripción de calcitriol en pacientes } \\
\text { con ERC en estadios del G3a al G5 sin requerimiento de } \\
\text { diálisis y su uso debe ser individualizado.] }\end{array}$ & 95,7 \\
\hline $\begin{array}{l}\text { Se sugiere: [La prescripción y el uso de análogos de vitamina } \\
\text { D en pacientes con ERC con niveles normales de vitamina D } \\
\text { y aumento progresivo de PTH.] }\end{array}$ & 97,9 \\
\hline $\begin{array}{l}\text { Se sugiere: [Considerar el uso de calcitriol en pacientes con } \\
\text { ERC en estadios del G4 al G5 con hiperparatiroidismo severo } \\
\text { y progresivo, así como en pacientes en estadio G5 de la ERC } \\
\text { como estrategia para controlar niveles de PTH.] }\end{array}$ & 93,6 \\
\hline $\begin{array}{l}\text { Se sugiere: [Considerar la elección de análogos selectivos de } \\
\text { vitamina D sobre los no selectivos en pacientes con } \\
\text { enfermedad cardiovascular establecida, como estrategia de } \\
\text { prevención secundaria.] }\end{array}$ & 95,7 \\
\hline
\end{tabular}




\begin{tabular}{|c|c|}
\hline $\begin{array}{l}\text { En caso de pacientes con ERC en estadios del G3 al G5 en } \\
\text { diálisis y calcificación vascular se sugiere: [Utilizar análogos } \\
\text { selectivos de vitamina D.] }\end{array}$ & 95,7 \\
\hline $\begin{array}{l}\text { Se sugiere: [El uso de calcimiméticos en pacientes con ERC } \\
\text { en estadio G5 en diálisis con niveles aumentados de PTH, en } \\
\text { monoterapia o en combinación con análogos de la vitamina } \\
\text { D.] }\end{array}$ & 93,6 \\
\hline $\begin{array}{l}\text { Se sugiere: [Uso de calcimiméticos disponibles en Colombia } \\
\text { en casos de hiperfosfatemia o hipercalcemia persistente en } \\
\text { pacientes con PTH elevada.] }\end{array}$ & 95,7 \\
\hline $\begin{array}{l}\text { En el caso de hipocalcemia persistente con el uso de } \\
\text { calcimiméticos, se sugiere: [Considerar disminuir la dosis o } \\
\text { adicionar suplementos de calcio.] }\end{array}$ & 87,2 \\
\hline $\begin{array}{l}\text { Se recomienda: [Prevenir la hipercalcemia y la acidosis } \\
\text { metabólica dentro de las estrategias de prevención de } \\
\text { calcifilaxis, además de considerar la concentración de calcio } \\
\text { en el líquido de diálisis y los medicamentos a base de calcio } \\
\text { como los quelantes de fósforo cálcicos y análogos no } \\
\text { selectivos de vitamina D.] }\end{array}$ & 100,0 \\
\hline $\begin{array}{l}\text { Se sugiere: [Evitar la anticoagulación con antagonistas de la } \\
\text { vitamina K, en pacientes con calcificación vascular por el } \\
\text { riesgo de calcifilaxis.] }\end{array}$ & 93,6 \\
\hline $\begin{array}{l}\text { En pacientes con requerimiento de anticoagulación se } \\
\text { sugiere: [Evitar el uso de análogos no selectivos de vitamina }\end{array}$ & 87,2 \\
\hline
\end{tabular}




\begin{tabular}{|c|c|}
\hline D.] & \\
\hline $\begin{array}{l}\text { Se sugiere: [Que el manejo de calcifilaxis sea individualizado, } \\
\text { considerando las indicaciones de alternativas disponibles en } \\
\text { el contexto y el análisis de riesgo-beneficio para el paciente.] }\end{array}$ & 100,0 \\
\hline $\begin{array}{l}\text { Se sugiere: [Como alternativas de tratamiento de calcifilaxis } \\
\text { el tiosulfato de sodio, la paratiroidectomía, los calcimiméticos, } \\
\text { terapia de oxígeno hiperbárico y bifosfonatos.] }\end{array}$ & 97,9 \\
\hline $\begin{array}{l}\text { Se sugiere: [Que se consideren todas las terapias disponibles } \\
\text { en monoterapia o en combinación para el manejo de } \\
\text { calcifilaxis.] }\end{array}$ & 95,7 \\
\hline $\begin{array}{l}\text { Se recomienda: [Que la paratiroidectomía sea indicada en } \\
\text { pacientes con ERC en estadios del G3 al G5 e } \\
\text { hiperparatiroidismo secundario severo cuando otras } \\
\text { alternativas de tratamientos médico conservador sean } \\
\text { inefectivas.] }\end{array}$ & 91,5 \\
\hline $\begin{array}{l}\text { Se sugiere: [Considerar la paratiroidectomía como estrategia } \\
\text { de manejo ante PTH persiste (PTHi persistentemente > } 800 \\
\mathrm{pg} / \mathrm{mL} \text { ), hipercalcemia persistente cuando otras alternativas } \\
\text { de tratamiento médico conservador han sido inefectivas, } \\
\text { aumento de glándula paratiroides y ante resistencia a la } \\
\text { vitamina D activa y sus análogos.] }\end{array}$ & 91,5 \\
\hline $\begin{array}{l}\text { Se recomienda: [La paratiroidectomía en pacientes } \\
\text { trasplantados con hipercalcemia persistente, aunque debe } \\
\text { ser la última alternativa de elección.] }\end{array}$ & 91,5 \\
\hline Se sugiere: [Manejo médico conservador de la hipercalcemia & 97,9 \\
\hline
\end{tabular}




\begin{tabular}{|c|c|}
\hline con calcimiméticos.] & \\
\hline $\begin{array}{l}\text { Se recomienda: [Realizar osteodensitometría ósea a } \\
\text { pacientes con ERC en estadios del G3a al G5D con } \\
\text { evidencia de AMOM-ERC con o sin factores de riesgo de } \\
\text { osteoporosis.] }\end{array}$ & 89,4 \\
\hline $\begin{array}{l}\text { Se recomienda: [El uso de bifosfonatos en pacientes con } \\
\text { ERC en estadios del G1 al G3 (TFG } \geq 30 \mathrm{~mL} / \mathrm{min} / 1,73 \mathrm{~m}^{2} \text { ), } \\
\text { así como en pacientes en estadios del G3 al G4 con } \\
\text { anormalidades bioquímicas relacionadas con AMOM-ERC y } \\
\text { baja densidad mineral con o sin fracturas.] }\end{array}$ & 93,6 \\
\hline $\begin{array}{l}\text { Se recomienda: [El uso de vitamina D activa o sus análogos } \\
\text { para pacientes con ERC en estadios G1 y G2 y osteoporosis, } \\
\text { así como en pacientes en estadios del G3a al G3b con } \\
\text { niveles de PTH normales, osteoporosis con o sin riesgo de } \\
\text { fractura.] }\end{array}$ & 91,5 \\
\hline $\begin{array}{l}\text { Se recomienda: [Considerar la magnitud y la reversibilidad de } \\
\text { las anormalidades bioquímicas y la progresión de la } \\
\text { enfermedad renal durante la prescripción de vitamina D en } \\
\text { pacientes en estadios del G3b al G5 con anormalidades } \\
\text { bioquímicas de AMOM-ERC, baja densidad ósea y fracturas } \\
\text { por fragilidad.] }\end{array}$ & 95,7 \\
\hline $\begin{array}{l}\text { No se recomienda: [El uso de bifosfanatos en pacientes con } \\
\text { ERC en estadio G5 con enfermedad ósea adinámica.] }\end{array}$ & 91,5 \\
\hline
\end{tabular}




\begin{tabular}{|l|c|}
\hline $\begin{array}{l}\text { Se sugiere: [Considerar el estadio de la ERC para la elección } \\
\text { del bifosfonato.] }\end{array}$ & 97,9 \\
\hline Se sugiere: [El uso de PTH recombinante en mujeres con & 87,2 \\
masculina primaria, deterioro sexual u osteoporosis inducida & \\
por glucocorticoides.] & 100,0 \\
\hline $\begin{array}{l}\text { Se recomienda: [La medición de la densidad ósea mineral en } \\
\text { pacientes trasplantados con riesgo de osteoporosis.] }\end{array}$ & 100,0 \\
\hline $\begin{array}{l}\text { Se recomienda: [Que el tratamiento de pacientes } \\
\text { trasplantados y con osteoporosis sea individualizado, } \\
\text { considerando la presencia de AMOM-ERC y el tipo de } \\
\text { medicamentos disponibles.] }\end{array}$ & 93,6 \\
\hline $\begin{array}{l}\text { Se sugiere: [Considerar entre las alternativas de tratamiento } \\
\text { de paciente con trasplante renal y osteoporosis: vitamina D, } \\
\text { bifosfonatos, denosumab y calcitonina, de acuerdo con el } \\
\text { riesgo individual.] }\end{array}$ & \\
\hline
\end{tabular}

Fuente: elaboración propia. 


\section{Resultados de la votación de consenso de expertos (ronda 1 y 2)}

\begin{tabular}{|c|c|}
\hline \multicolumn{2}{|l|}{$1^{\text {era }}$ ronda de consenso } \\
\hline Recomendación & $\begin{array}{l}\% \\
\text { acuerdo }\end{array}$ \\
\hline Se sugiere realizar mediciones anuales de calcio, fósforo, PTH en & $72 \%$ \\
\hline $\begin{array}{l}\text { pacientes con estadios G1 y G2 de la ERC como estrategia para } \\
\text { diagnóstico temprano y prevención de complicaciones vasculares } \\
\text { en pacientes con diabetes, hipertensión o antecedentes de evento } \\
\text { cardiovascular. }\end{array}$ & \\
\hline $\begin{array}{l}\text { Se sugiere realizar tomografía computarizada de tórax de cortes } \\
\text { múltiples para la detección de calcificaciones en las arterias } \\
\text { coronarias, considerando la disponibilidad de la tecnología y el } \\
\text { juicio clínico. }\end{array}$ & $83 \%$ \\
\hline $\begin{array}{l}\text { Se recomienda evitar el uso rutinario de quelantes de fósforo a } \\
\text { base de calcio o de aluminio para pacientes con ERC en estadios } \\
\text { del G3a al G5D, considerando el contexto del paciente. }\end{array}$ & $55 \%$ \\
\hline $\begin{array}{l}\text { Se sugiere el uso de bloqueadores de absorción de fósforo en } \\
\text { pacientes con ERC estadio 5, en terapia con hemodiálisis de } \\
\text { mantenimiento y niveles de fosfato sérico persistentemente } \\
\text { elevados a pesar de tratamiento con quelantes de fósforo y dieta. }\end{array}$ & $86 \%$ \\
\hline
\end{tabular}




\begin{tabular}{|c|c|}
\hline \multicolumn{2}{|l|}{$2^{\text {da }}$ ronda de consenso } \\
\hline Recomendación & $\%$ \\
\hline $\begin{array}{l}\text { Se sugiere considerar mediciones anuales de calcio, fósforo y PTH } \\
\text { desde estadios tempranos de ERC (G1 y G2), dado su papel como } \\
\text { factores de riesgo y marcadores de enfermedad cardiovascular y } \\
\text { ósea, como parte de la evaluación clínica integral del paciente. }\end{array}$ & 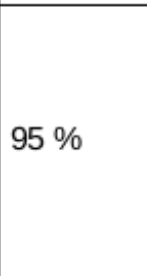 \\
\hline $\begin{array}{l}\text { Se recomienda evitar el uso rutinario de quelantes de fósforo a } \\
\text { base de calcio para pacientes con ERC en estadios del G3a al }\end{array}$ & $100 \%$ \\
\hline G5D, considerando el contexto del paciente. & \\
\hline $\begin{array}{l}\text { Se sugiere considerar el uso de quelantes de fósforo a base de } \\
\text { aluminio por periodos inferiores a tres meses en aquellos pacientes } \\
\text { en que fallaron las medidas no farmacológicas y donde los niveles } \\
\text { de fosfato se encuentren fuera de metas establecidas para el } \\
\text { estadio de la ERC. Punto de buena práctica. }\end{array}$ & $100 \%$ \\
\hline
\end{tabular}

Fuente: elaboración propia. 


\section{Lista completa de autores}

\section{Autores principales}

Grupo desarrollador - expertos clínicos

Jorge Antonio Coronado Daza (iD 1,2,3, Erica Yamile Yama Mosquera (iD 1,4,5, Mercedes Alfaro Tejeda (D) 1,6, Juan Guillermo Guevara García (D) ${ }^{1}$, Astrid Patricia Hernández Sierra (iD) , José Javier Arango Álvarez ${ }^{1}$, Elizabeth Álzate Herrera (D)1, Andrés Hernández Coronado (D)1, Cesar Augusto Restrepo Valencia (D) 1,7, Gustavo Aroca Martínez iD 1,12,30

Grupo desarrollador - expertos metodológicos

Kelly Rocío Chacón Acevedo iD 8,9,10, María Paula Gutiérrez Sepúlveda iD 9,10

\section{Expertos clínicos}

Asociación Colombiana de Nefrología e Hipertensión Arterial

Adolfo Pertuz Pinzón (D)1,11, Alejandro Duran Camero ${ }^{1,36}$, Álvaro José González Vélez ${ }^{1,37}$, Amable Duran Palmar (D)1, Angélica Roncallo Del Castillo (D) 1,11, Armando Rafael Ramos Guette ${ }^{\text {DD }}{ }^{1,11}$, Arnaldo Arrieta Benedetti ${ }^{1,11}$, Carlos Alcocer Fernández (D) 1,13, Carolina Larrarte Arenas (iD) 1,14,15, Efraín Puche Martínez (D) 1,11, Elkin Machacón Miranda (iD 1,16, Emiro Solórzano Anaya (DD 1,16, Genaro Gomez Torres ${ }^{1,19}$, Hernán Martínez Puello iD ${ }^{1,20}$, Ignacio Villanueva Bendek (iD 1,16, Iván Villegas Gutierrez ${ }^{1,21}$, Jairo Hernán González Bautista (iD) ${ }^{\text {, Joa- }}$ quin Roberto Rodelo Ceballos (DD 1,22, Joel José Ortega Mendoza (iD) ${ }^{1}$, Jorge Rico Fontalvo (D) 1,11, José López Garcés (iD 1,24, Juan Conde Manotas (iD) 1 , Juan Gélvez Rueda (iD 1,25, Kateir Contreras Villamizar (iD 1,8, Luis Alfonso Cano Marin (D) 1,11 , Luis Cotes Araujo (D) ${ }^{1,28}$, Luis Puello Gonzalez (DD 1,6 , Luis Barros Camargo (D) 1 , Luis Valderrama Cometa (iD) 1,11 , Manuel Cueto Chaparro iD 1, María Gómez Canabal (iD) 1,11, Milene Patricia Angulo Juliao iD 1, Nancy Yomayusa Gonzalez (iD $1,9,10$, Natalia Malaver Jimenez (iD 1,29, Omar de Jesús Cabarcas Barbosa (D) 1,30, Orlando Olivares Algarin (iD $1,2,3$, Ramón Duque Arrázola ${ }^{1,31}$, Roberto Ramírez Marmolejo (D) 1,32, Rodrigo Daza Arnedo (D) 1,11, Sheila Builes Rodriguez ${ }^{\text {ID } 1,33}$, Victor Manuel De La Espriella Badel (D) 1,11,35, Vladimir Rico García (iD) 1,11 
Sociedad Colombiana de Cardiología y Cirugía Cardiovascular

Fernán del Cristo Mendoza Beltrán (iD 17,18, Fernando Manzur Jattin (iD)2

Asociación Colombiana de Gerontología y Geriatría

Leidy Yoana Aristizábal Gomez iD 27

Asociación Colombiana de Medicina Interna

Tatiana Lucia Espinosa Espitia (iD 34 , Heli Hernández Ayazo (iD2

Asociación Colombiana de Endocrinología, Diabetes y Metabolismo

Alejandro Román González (D) 23

Asociación Colombiana de Reumatología

Carlo V Caballero-Uribe iD 12 , Rita Sierra Merlano iD 2

${ }^{1}$ Asociación Colombiana de Nefrología e Hipertensión Arterial (Asocolnef).

${ }^{2}$ Facultad de Medicina, Departamento médico, Universidad de Cartagena.

${ }^{3}$ Nefrología y Diálisis SAS, Cartagena, Colombia.

${ }^{4}$ Universidad Nueva Granada, Bogotá, Colombia.

${ }^{5}$ Clínica Reina Sofía, Bogotá, Colombia.

${ }^{6}$ Corporación Universitaria Rafael Núñez, Cartagena, Colombia.

${ }^{7}$ Universidad de Caldas, Manizales, Colombia.

${ }^{8}$ Universidad Nacional de Colombia.

${ }^{9}$ Instituto Global de Excelencia Clínica, Keralty Colombia.

10 Grupo de Investigación Traslacional, Keralty.

${ }^{1} 1$ Fresenius Medical Care, Colombia.

12 Universidad del Norte, Barranquilla, Colombia.

${ }^{13}$ IPS Bonanza - Health Care, Turbaco, Colombia.

${ }^{14}$ RCS, Colombia.

${ }^{15}$ Hospital Militar Central, Bogotá, Colombia. ${ }^{16}$ DAVITA, Colombia.

17 Sociedad Colombiana de Cardiología.

18 Fundación Clínica Shaio, Colombia. 
19 Unidad Renal Sumuywajat, Maicao, Colombia.

${ }^{20}$ RCS Colombia, Barranquilla, Colombia.

${ }^{21}$ Nefrodiálisis SAS, Medellín, Colombia.

${ }^{22}$ Hospital San Vicente Fundación, Medellín, Colombia.

${ }^{23}$ Facultad de Medicina, Universidad de Antioquia.

${ }^{24}$ Clínica Victoriana, Medellín, Colombia.

${ }^{25}$ Fundación Cardiovascular de Colombia.

${ }^{26}$ Hospital Universitario San Ignacio, Bogotá, Colombia.

27 Asociación colombiana de geriatría y gerontología.

${ }^{28}$ Clínica porto azul, Barranquilla, Colombia.

${ }^{29}$ Clínica del Country, Bogotá, Colombia.

${ }^{30}$ Universidad Simón Bolívar, Barranquilla, Colombia.

${ }^{31}$ Baxter, Colombia.

${ }^{32}$ Universidad Santiago de Cali, Colombia.

33 NOVASALUD CARIBE IPS, Barranquilla, Colombia.

${ }^{34}$ Asociación Colombiana de Medicina Interna.

${ }^{35}$ Medisinu, Montería, Colombia.

${ }^{36}$ Universidad El Bosque, Bogotá, Colombia.

${ }^{37}$ Centro de Diálisis Santa Margarita, Barranquilla, Colombia. 